\title{
Ultra-stable all-solid-state sodium-metal batteries enabled by perfluoropolyether-based electrolytes
}

Xiaoen WANG ( $\nabla$ xiaoen.wang@deakin.edu.au )

Deakin University

\section{Cheng Zhang}

The University of Queensland

\section{Michal Sawczyk}

University of Illinois at Chicago https://orcid.org/0000-0002-0827-4036

Qinghong Yuan

The University of Queensland

\section{Fangfang Chen}

Deakin University

Tiago Mendes

Deakin University

\section{Patrick Howlett}

Deakin University https://orcid.org/0000-0002-2151-2932

\section{Changkui Fu}

The University of Queensland

\section{Debra Searles}

The University of Queensland

\section{Petr Kral}

Univ Illinois

\section{Craig Hawker}

UC - Santa Barbara https://orcid.org/0000-0001-9951-851X

Andrew Whittaker

University of Queensland

\section{Maria Forsyth}

Deakin University https://orcid.org/0000-0002-4273-8105

\section{Article}

Keywords: batteries, solid polymer electrolytes, perfluoropolyether

Posted Date: March 26th, 2021 
DOl: https://doi.org/10.21203/rs.3.rs-354912/v1

License: (c) (1) This work is licensed under a Creative Commons Attribution 4.0 International License. Read Full License 


\section{$1 \quad$ Ultra-stable all-solid-state sodium-metal batteries enabled}

2 by perfluoropolyether-based electrolytes

3 Xiaoen Wang,* Cheng Zhang,* Michal Sawczyk, Qinghong Yuan, Fangfang Chen,

4 Tiago C. Mendes, Patrick C. Howlett, Changkui Fu, Debra J. Searles, Petr Král, Craig

5 J. Hawker, Andrew K. Whittaker,* and Maria Forsyth*

6

7 Dr. X. Wang, Dr. F. Chen, Dr. T. C. Mendes, Prof. P. C. Howlett,

8 Prof. M. Forsyth

9 Institute for Frontier Materials (IFM)

10 Deakin University

11 Geelong, VIC 3217, Australia.

12 E-mail: xiaoen.wang@deakin.edu.au; maria.forsyth@deakin.edu.au

13 Dr. C. Zhang, Dr. C. Fu, Prof A. K. Whittaker

14 ARC Centre of Excellence in Convergent Bio-Nano Science and Technology and 15 Australian Institute for Bioengineering and Nanotechnology

16 The University of Queensland

17 Brisbane, QLD 4072, Australia

18 E-mail: c.zhang3@uq.edu.au; a.whittaker@uq.edu.au

19 Dr. Q. Yuan, Prof. D. J. Searles

20 Australian Institute for Bioengineering and Nanotechnology

21 The University of Queensland

22 Brisbane, QLD 4072, Australia

23 Prof. D. J. Searles

24 School of Chemistry and Molecular Biosciences and Centre for Theoretical and

25 Computational Molecular Science

26 The University of Queensland

27 Brisbane, Queensland 4072, Australia

28 Dr. Q. Yuan

29 State Key Laboratory of Precision Spectroscopy

30 School of Physics and Material Science

31 East China Normal University

32 Shanghai 200062, P. R. China

33 M. Sawczyk, Prof. P. Král 
1 Department of Chemistry and Department of Physics, University of Illinois at Chicago, 2 Chicago, Illinois 60607, United States

3 Department of Biopharmaceutical Sciences, University of Illinois at Chicago, Chicago, 4 Illinois 60612, United States

5 Prof. C. J. Hawker

6 Materials Research Laboratory, Department of Materials, and Department of Chemistry 7 and Biochemistry

8 University of California, Santa Barbara

9 California 93106, United States 


\section{Abstract}

2 Rechargeable batteries paired with sodium (Na)-metal anodes are considered as one of

3 the most promising high energy and low-cost energy storage systems. However, the use

4 of highly reactive $\mathrm{Na}$ metal and the formation of $\mathrm{Na}$ dendrites during battery operation

5 have caused significant safety concerns, especially when highly flammable liquid

6 electrolytes are used. Herein, we design and develop a solvent-free solid polymer

7 electrolytes (SPEs) based on a perfluoropolyether (PFPE) terminated polyethylene

8 glycol (PEG)-based block copolymer for safe and stable all-solid-state Na-metal

9 batteries. Compared with traditional poly(ethylene oxide) (PEO) or PEG SPEs, our

10 results suggest that block copolymer design allows for the formation of self-assembled

11 microstructures leading to high storage modulus at elevated temperatures with the PEG

12 domains providing transport channels even at high salt concentration $\left(\mathrm{EO} / \mathrm{Na}^{+}=8: 2\right)$.

13 Moreover, it is demonstrated that the incorporation of PFPE segments enhances the $\mathrm{Na}^{+}$

14 transference number of the electrolyte to 0.46 at $80{ }^{\circ} \mathrm{C}$. Finally, the proposed SPE

15 exhibits highly stable symmetric cell cycling performance with high current density

$16\left(0.5 \mathrm{~mA} \mathrm{~cm}^{-2}\right.$ and $1.0 \mathrm{mAh} \mathrm{cm}^{-2}$, up to 1300 hours $)$. The assembled all-solid-state Na-

17 metal batteries with $\mathrm{Na}_{3} \mathrm{~V}_{2}\left(\mathrm{PO}_{4}\right)_{3}$ cathode demonstrate outstanding rate performance,

18 high capacity retention and long-term charge/discharge stability $(\mathrm{CE}=99.91 \%)$ after 19 more than 900 cycles. 


\section{Introduction}

Sodium (Na) ion batteries are recognized as attractive energy storage devices for next generation large-scale applications due to the high abundance and wide distribution of Na resources. ${ }^{1,2}$ In addition, benefiting from its high theoretical specific capacity (1165 $\left.\mathrm{mAh} \mathrm{g}^{-1}\right)$ and low redox potential $(-2.714 \mathrm{~V} v s$ standard hydrogen electrode), the use of $\mathrm{Na}$ metal as anodes further boosts the overall battery capacity, enabling the next generation of low-cost, high-capacity batteries. ${ }^{3-5}$ However, the development of Nametal batteries faces significant challenges. ${ }^{6,7}$ For instance, the extensive use of highly flammable liquid carbonate electrolytes can lead to catastrophic hazards such as fire and explosions. Furthermore, these organic solvent based electrolytes do not support stable long term cycling of $\mathrm{Na}$ metal.

In contrast, the development of all solid-state Na-metal batteries with the absence of any flammable liquid shows significant advantages for improving battery safety. Several strategies have been intensively investigated including solid-state inorganic $\mathrm{Na}^{+}$conductors such as sulfides ( $\left.\mathrm{Na}_{3} \mathrm{PS}_{4}\right)$, NASICON and $\beta$-alumina. ${ }^{8}$ Although these inorganic conductors show remarkable conductivity at room temperature and suitable electrochemical stability, ${ }^{9}$ the physical point-to-point contacts at the electrolyte/electrode interface are problematic as these insufficient contacts will dramatically increase interfacial resistance, leading to poor cycling stability and final battery failure. ${ }^{10}$ In addition, the ability of inorganic systems to suppress dendrite formation remains a continuing topic of debate as some recent work illustrates metallic dendrite growing through the inorganic electrolytes via material defects such as voids or cracks. ${ }^{10}$

As an alternative to rigid inorganic electrolytes, solvent-free polymer electrolytes are attractive due to their flexibility, suitable mechanical strength and high electrochemical stability. ${ }^{11-16}$ The traditional polymer electrolytes consist of a host polymer such as poly(ethylene oxide) (PEO) and Na salts. PEO-based solid polymer electrolytes (SPEs) show good $\mathrm{Na}$ salt solubility due to the coordination between ether oxygen and $\mathrm{Na}^{+}$, however, this interaction is relatively strong, which limits the $\mathrm{Na}^{+}$movements. As a result, low transference numbers $\left(t_{\mathrm{Na}}\right)$, defined as the ratio of current carried by $\mathrm{Na}^{+}$to the total current carried by all mobile charges, ${ }^{17}$ are obtained. Furthermore, due to the high reactivity of Na metal, poor interfacial stability between PEO electrolytes and the 
$1 \mathrm{Na}$ anode is another hindrance for achieving long life-time battery performance.

2 Previous studies have also demonstrated that the side reactions between the electrolyte and $\mathrm{Na}$ metal will result in an increase in interfacial resistance and subsequent battery failure during long-term cycling. With the aim of improving Na metal stability during operation, Hu and co-workers recently proposed an effective strategy to take advantage of NaFSI hydrolysis combined with $\mathrm{Al}_{2} \mathrm{O}_{3}$ nanoparticles. ${ }^{18}$ They confirmed that the side product of this composite electrolyte can effectively form a protective layer, leading to enhanced columbic efficiency and stable long term charge/discharge performance at 80 ${ }^{\circ} \mathrm{C}$. In addition, the emergence of fluorinated electrolytes provides an effective method to stabilize metal anodes and improve cycling stability. Wang et al. demonstrated that

11 a thin LiF-rich solid-electrolyte-interphase (SEI) layer can be formed when fluorinated liquid electrolytes are used. ${ }^{19}$ The advantages of fluorinated electrolytes were further confirmed through design of fluorinated ether electrolytes which enable long term cycling of Li-metal batteries. ${ }^{20-22}$ Moreover, Balsara and co-workers demonstrated that the interactions between fluorinated segments and salt anions can effectively enhance the $\mathrm{Li}^{+}$transference number and $\mathrm{Li}^{+}$conductivity. ${ }^{23}$ Unfortunately, all of these previous reports focused on the design of fluorinated liquid electrolytes and their applications in lithium batteries. ${ }^{24}$ Examination of SPEs with fluorinated components and their applications on Na-metal batteries are yet to be investigated.

20 In this work, for the first time, a new class of fluorinated block copolymer is designed as a solid electrolyte for the development of highly stable, all-solid-state Na-metal batteries. We demonstrate that the introduction of perfluoropolyether (PFPE) domains into PEG-based electrolytes can effectively enhance the mechanical properties of polymer electrolytes due to the formation of self-assembled microstructures. Compared with traditional non-fluorinated PEG electrolytes, these new PFPE-based SPEs significantly improve $\mathrm{Na}^{+}$transport and increase the $\mathrm{Na}^{+}$transference number. More importantly, the presence of PFPE segments in the polymer electrolyte leads to outstanding cycling stability $(1000 \mathrm{~h})$ at $1.0 \mathrm{mAh} \mathrm{\textrm {cm } ^ { - 2 }}$ plating/striping capacity with $\mathrm{Na}$ metal anode. Finally, all-solid-state Na-metal batteries based on fluorinated SPE composites show promising rate capability and long-term stability, allowing over 900 cycles with an average coulombic efficiency of $99.91 \%$ at $80{ }^{\circ} \mathrm{C}$. The study promises opportunities for the design of new fluorinated copolymers as highly stable solid polymer electrolytes for Na-based battery applications 


\section{$1 \quad$ Results and discussion}

2 Rational Design, Structure and Thermal Properties of PFPE Electrolytes

(a)

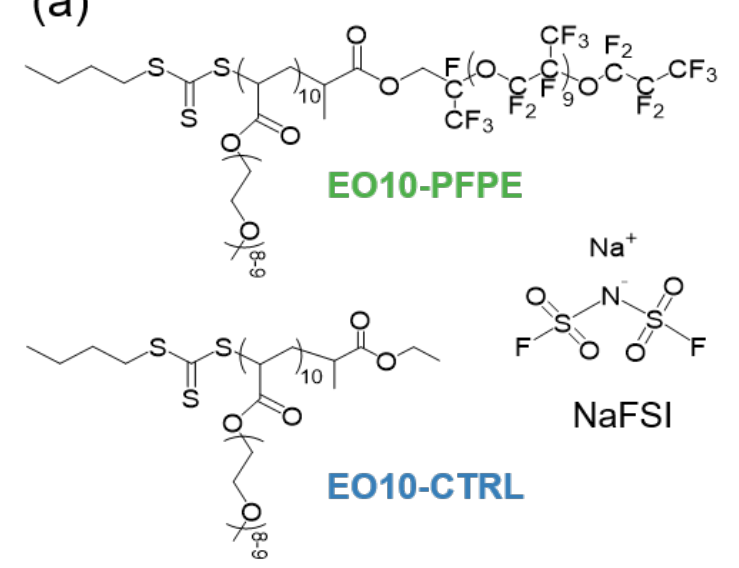

(c)
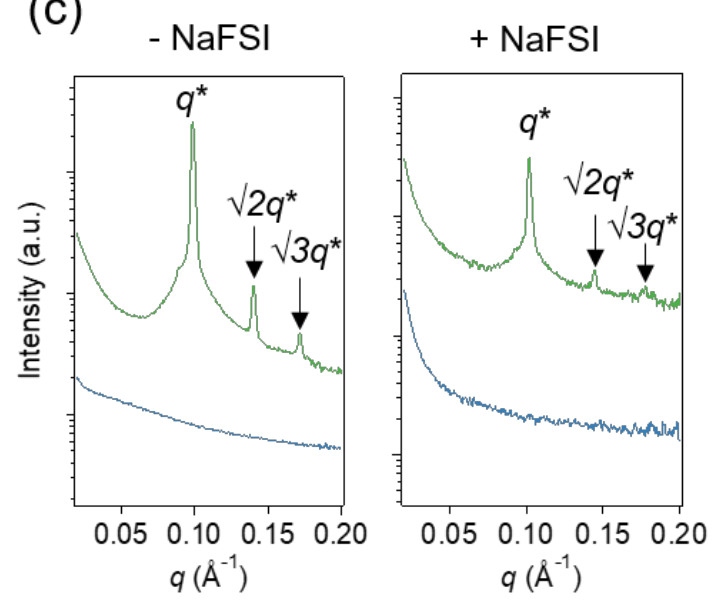

(b)

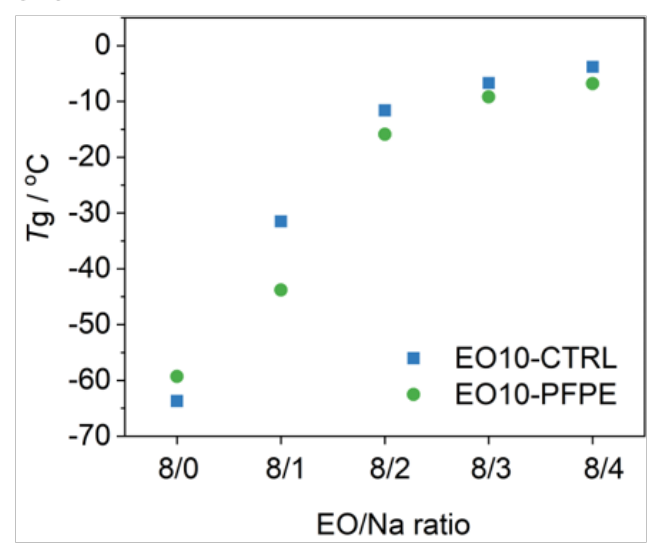

(d)

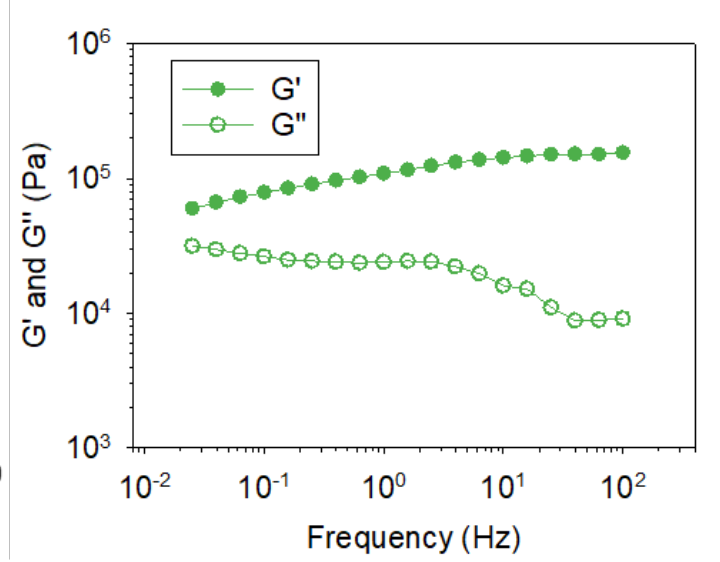

4 Figure 1. Chemical structures as well as physical and self-assembly properties of

5 PFPE-based polymer electrolytes. (a) Chemical structures of poly(PEGA) 10 -PFPE

6 (EO10-PFPE, green), control homopolymer poly(PEGA) 10 (EO10-CTRL, blue) and

7 NaFSI salt (red). (b) Dependence of glass transition temperature $\left(T_{g}\right)$ of PEG on EO/Na

8 ratios. (c) SAXS profiles showing self-assembled structures of EO10-CTRL and EO10-

9 PFPE with or without $\mathrm{NaFSI}$ at $80{ }^{\circ} \mathrm{C}$. (EO/Na $=8 / 2$, molar ratio). (d) Changes in

10 storage modulus $\left(G^{\prime}\right)$ and loss modulus $\left(G^{\prime \prime}\right)$ of EO10-PFPE as a function of frequency 11 at $80^{\circ} \mathrm{C}$.

12 We have designed and investigated a new class of fluorinated block copolymer with 13 controlled morphology as a SPE to enhance mechanical integrity, interfacial stability 14 and $\mathrm{Na}^{+}$transport. The copolymer consists of a PFPE-based segment as the fluorinated 15 block and oligo(ethylene glycol) methyl ether acrylate (PEGA) as the soft block 
1 (poly(PEGA)m-PFPE or EOm-PFPE, where $m$ is the degree of polymerization $(D P)$ of

2 PEGA). The synthetic details and characterization data for the copolymers are shown

3 in the experimental section and Table S1. ${ }^{25-34}$ Figure 1a illustrates the chemical

4 structures of PFPE polymer (EO10-PFPE) and control polymer (EO10-CTRL). In this

5 strategy, the dissociated $\mathrm{Na}^{+}$ions in the PEG domain undergo efficient transport with

6 the assistance of ether oxygen side chain relaxation, while the phase separation between

7 the PEG and PFPE blocks maintains the mechanical integrity. The fluorinated segments

8 are also designed to stabilize the alkali metal anode, Na metal in this study, through the

9 potential for formation of stable fluorinated compounds in the SEI layer. ${ }^{35}$

The interactions between polymers and alkali metal ions play a crucial role in the

11 determination of polymer electrolyte properties and thus the battery performance.

12 Previous reports have shown that the strength of coordination between the ether oxygen

13 groups of the PEG backbone and alkali metal ions significantly affect the physical 14 properties of the resultant polymer electrolytes. ${ }^{36}$ The investigation of thermal behavior 15 i.e. glass transition temperature $\left(T_{\mathrm{g}}\right)$ can ultimately help to understand such interactions 16 in different electrolyte systems. For example, differential scanning calorimetry (DSC) 17 measurements of neat EO10-PFPE copolymers show a glass transition temperature $\left(T_{\mathrm{g}}\right)$ 18 at $-59.3{ }^{\circ} \mathrm{C}$ and an endothermic melting peak $\left(T_{\mathrm{m}}\right)$ located between -20 to $20{ }^{\circ} \mathrm{C}$ (Figure $19 \mathrm{~S} 1, \mathrm{~S} 2$ ), associated with the glass-to-rubber relaxation and melting of the PEG domains, 20 respectively. The glass transition and melt characteristics are well maintained in all 21 PFPE-containing block polymers with different DPs of PEGA. Significantly, after adding NaFSI salt, the melting peak of PFPE polymers completely disappears (Figure $\mathrm{S} 1)$. Another notable change is that, due to the strong coordination between ether oxygen and $\mathrm{Na}^{+}$ions, the addition of NaFSI increases the $T_{\mathrm{g}}$ of the PEG segments dramatically from $\approx-60$ to above $-40{ }^{\circ} \mathrm{C}$ for all four of the EOm-PFPE copolymers $(\mathrm{m}$ $=5,10,20,40$ ) (Figure S2). A further investigation shows that the $T_{g}$ of these copolymer electrolytes highly depends on the salt concentration. As displayed in Figure $1 b$, Figure S3 and Table S2, increasing the NaFSI concentration lifts $T_{g}$ continuously

30 PFPE electrolyte. The shift in $T_{g}$ to higher temperatures indicates enhanced 31 conformational constraints of the PEG segment relaxation processes at high 32 concentration of salts, leading to reduced polymer flexibility and increased $T_{g}{ }^{36} \mathrm{In}$ 33 addition, a relatively small $T_{\mathrm{g}}$ increase rate in the high salt content region is observed 
1 (8/2 to $8 / 4$, Figure 1 b), indicating the approach to a maximum coordination of ions in 2 the PEG domains. ${ }^{37}$

3 Another important observation is that the introduction of the PFPE blocks enhances the 4 relaxation of the PEG domain due to the formation of self-assembled structures. 5 Compared with EO10-CTRL electrolyte, the EO10-PFPE with same EO/ $\mathrm{Na}^{+}$ratio 6 shows a lower $T_{g}$ (Figure 1b, Figures S3-S4 and Table S2) when NaFSI is added. We ascribe the relatively lower $T_{g}$ to confinement effects on the dynamics of the EO-Na complex, which is in good agreement with previously reported hybrid electrolyte systems. ${ }^{38,39}$ As shown in Figure 1c, the introduction of the PFPE block into PEG leads to the formation of self-assembled body-centered cubic (BCC) microstructures. The

11 presence of confinement in the microstructures allows the physical properties of 12 polymer electrolyte materials such as $T_{g}$, mobile diffusivity and molecular packing 13 density to be modulated. ${ }^{40-43}$ For instance, a larger free volume and separated phase 14 with enhanced dynamics are suggested in confined silica nano pores. ${ }^{38,44}$ Similarly, when NaFSI is added into EO10-PFPE, the EO-Na ${ }^{+}$complex will be mainly located in the PEG domains, therefore the confinement effects in self-assembled structures will provide more free volume, resulting in a lower $T_{g} .{ }^{38}$ Meanwhile the self-assembled BCC structures of EO10-PFPE electrolyte are maintained at higher temperatures with an order-disorder transition temperature $\left(T_{\mathrm{ODT}}\right)$ at $100{ }^{\circ} \mathrm{C}$, as determined by dynamic mechanical thermal analysis (DMTA, Figure S4). Figure 1d shows the frequency sweep storage $\left(G^{\prime}\right)$ and loss modulus $\left(G^{\prime \prime}\right)$ of EO10-PFPE electrolytes at $80^{\circ} \mathrm{C} . G^{\prime}$ is distinctly greater than $G^{\prime \prime}$ in the full frequency window $\left(10^{-2}-10^{2} \mathrm{~Hz}\right)$, implying a solid-like behavior of the EO10-PFPE electrolyte even at $80{ }^{\circ} \mathrm{C}$. In addition, the storage modulus

$24 G^{\prime}$ is closer to the loss modulus $G^{\prime \prime}$ at lower frequencies, indicating the soft behavior of the electrolyte, potentially allowing the PFPE electrolyte to adapt and achieve good contact with the electrodes, even with the unpredictable volume changes that may occur during cycling. ${ }^{45}$ This mechanical integrity at elevated temperatures is highly desirable for all solid battery devices and applications. ${ }^{46}$ 

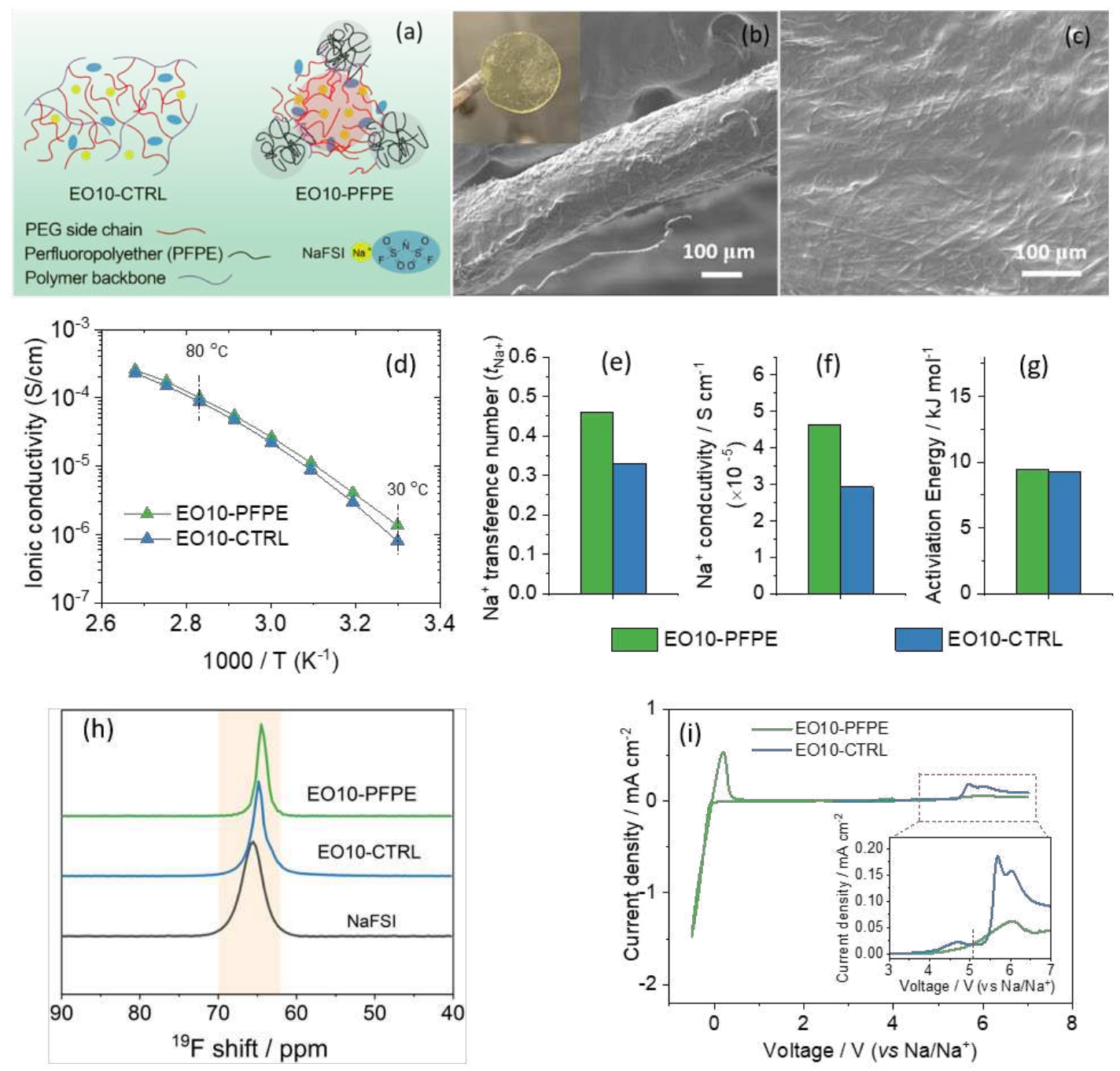

4 Figure 2. (a) Schematic illustration of proposed microstructures for EO10-CTRL and 5 EO10-PFPE electrolytes as suggested by SAXS data in Figure 1c. (b) Cross-sectional 6 SEM image of EO10-PFPE composite SPE. Inset is the photo of a free-standing 7 membrane. (c) Surface SEM image of EO10-PFPE composite SPE. (d) Comparison of 8 ionic conductivity of EO10-PFPE and EO10-CTRL composite electrolytes. (e-f) 9 Comparison of $\mathrm{Na}^{+}$transference number $\left(t_{\mathrm{Na}+}\right), \mathrm{Na}^{+}$conductivity and activation energy $10\left(E_{a}\right)$ of EO10-PFPE and EO10-CTRL electrolytes. $t_{\mathrm{Na}}$ was reported at $80{ }^{\circ} \mathrm{C}$. (h) ${ }^{19} \mathrm{~F}$ 11 NMR spectra of EO10-PFPE, EO10-CTRL electrolytes and NaFSI salt. (i) Cyclic 12 voltammetry (CV) and linear sweep voltammetry (LSV) profiles of EO10-PFPE 13 composite SPE. The LSV scan of EO10-CTRL composite electrolyte is also compared. 14 The scanning rate is $1 \mathrm{mV} / \mathrm{s}$ at $80^{\circ} \mathrm{C}$. 
1 Based on the SAXS results in Figure 1c, the microstructures of EO10-CTRL and EO10-

2 PFPE electrolytes are illustrated in Figure 2a. Compared with the liquid-like EO10-

3 CTRL electrolyte (Figure S6), the introduction of the PFPE block leads to the formation

4 of a solid-state material with phase-separated microstructure (PFPE-rich and PEG-

5 NaFSI-rich domains). ${ }^{47,}{ }^{48}$ Further incorporation of poly(vinylidene fluoride) (PVDF)

6 electrospun fibers (scanning electron microscope (SEM) image shown later in Figure

7 4a) results in a free-standing electrolyte membrane with thickness around $100 \mu \mathrm{m}$ (inset

8 in Figure $2 b$ ). Furthermore, the SEM images in Figure $2 b$ and $2 c$ confirm the pores of

9 the PVDF matrix are completely filled with EO10-PFPE electrolyte, leading to a

10 flexible solvent-free SPE that is highly desirable for solid-state battery devices. By

11 contrast, the EO10-CTRL composite is a soft and non-free-standing membrane which

12 deforms easily, even in the absence of external force (Figure S6).

13 As shown in Figure 2d, the conductivity of EO10-PFPE SPE is increased when 14 compared to that of the parent EO10-CTRL electrolyte over the whole temperature 15 range, with the conductivity of EO10-PFPE reaching $1.0 \times 10^{-4} \mathrm{~S} \mathrm{~cm}^{-1}$ at $80{ }^{\circ} \mathrm{C}$. Given 16 the fact that the conductivity reported here is the apparent conductivity and the volume 17 fraction of PEG phase is less than $100 \%(\sim 85 \%$, Table S1), we expect that the true 18 conductivity of PEG-rich phase in EO10-PFPE is much higher than the conductivity 19 reported in Figure 2d (see Figure S7 for normalized conductivity of EO10-PFPE).This 20 enhanced conductivity could originate from the relatively low $T_{g}$ (Figure $1 \mathrm{~b}$ ) which 21 facilitates the ion transport. ${ }^{38}$ Another benefit of introducing PFPE into the polymer 22 backbone is seen by the increased $\mathrm{Na}^{+}$transference number $\left(t_{\mathrm{Na}+}\right)$. As shown in Figure $232 \mathrm{e}, t_{\mathrm{Na}+}$ of EO10-PFPE is 0.48 at $80^{\circ} \mathrm{C}$, much higher than EO10-CTRL $\left(0.33\right.$ at $\left.80{ }^{\circ} \mathrm{C}\right)$. 24 Due to the higher $t_{\mathrm{Na}}$ and higher conductivity, the EO10-PFPE shows increased $\mathrm{Na}^{+}$ 25 conductivity (total conductivity $\times t_{\mathrm{Na}}$ ) of $4.7 \times 10^{-5} \mathrm{~S} \mathrm{~cm}^{-1}, 1.5$ times higher than that of 26 EO10-CTRL electrolyte (Figure 2f). The Vogel-Fulcher-Tamman (VFT) fitting results 27 in Figure 2e indicates that there is no significant change in activation energy in these 28 two electrolytes. The role of PFPE segments is highlighted by the NMR results in 29 Figure $2 \mathrm{~h}$. As one moves from NaFSI to EO10-CTRL-NaFSI to EO10-PFPE-NaFSI, 30 an upfield shift in ${ }^{19} \mathrm{~F}$ NMR resonance is observed which correlates with stronger ion 31 solvation or an increase in ion pairing, i.e. increased interactions between FSI anions 32 and PFPE polymer in this case. ${ }^{20,21,49-51}$ This anion-polymer interaction limits FSI 33 mobility and enhances $t_{\mathrm{Na}+}$, which is in good agreement with previous studies of lithium 
1 electrolytes as reported by Balsara and co-workers. ${ }^{23,47}$

2 Electrochemical stability of the electrolyte materials is crucial to sustain high 3 performance and reversibility of electrochemical reactions during Na battery operation.

4 The $\mathrm{CV}$ results shown in Figure $2 \mathrm{i}$ confirm a reversible plating and stripping process 5 and absence of significant oxidation $(<4.0 \mathrm{~V})$ when EO10-PFPE electrolyte is used.

6 Furthermore, linear sweep voltammetry (LSV) shows the electrochemical stability 7 window of EO10-PFPE is approximately $4.5 \mathrm{~V}$ (inset of Figure 2i), sufficient for most 8 Na battery applications. ${ }^{52}$ It is noteable that compared with EO10-CTRL, the EO109 PFPE shows a much lower oxidation current until $5 \mathrm{~V}$, indicative of superior oxidative stability under high voltage conditions. We attribute this increased oxidation stability

11 to the formation of PFPE-rich domains with high oxidation stability. ${ }^{21,53}$ As suggested 12 by Bao et al, ${ }^{21}$ the formation of PFPE-rich domains via self-assembly limits the contact 13 of ethylene oxide repeat units with the electrode surface and protects the electrolyte 14 from further oxidation at high voltage. These results highlight the potential for 15 introducing PFPE domains in PEG electrolytes and the benefits from formation of a 16 phase-separated structure as an effective strategy for enhancing the electrochemical 17 stability and $\mathrm{Na}^{+}$transport properties of polymer electrolytes.

19 Molecular dynamics (MD) simulations were then performed in order to further 20 understand the interactions between NaFSI and the polymer matrix. ${ }^{54}$ Therein, we 21 separately studied the behavior of concentrated solutions of EO-PFPE and EO-CTRL 22 in diethyl ether, with $\mathrm{Na}^{+}$and $\mathrm{FSI}^{-}$ions. During the simulations, both polymers readily 23 formed complexes with $\mathrm{Na}^{+}$and $\mathrm{FSI}^{-}$ions with folded polymer structures being 24 observed (Supplementary Figure S12-S13). Although the original experiments were conducted without the presence of an organic solvent, this approach allowed better 26 equilibration of the polymer structure by increasing side-chains flexibility in the 27 presence of solvent. Figures 3a-b show the different structures formed after $200 \mathrm{~ns}$ 28 simulation time with the hydrophobic fluorinated chains closely packed at the surface, 29 whereas the core of the assembly is composed of an ion-rich phase. For the EO-CTRL 30 electrolyte, $\mathrm{Na}$ ions are evenly distributed in the whole polymer matrix, forming EO$31 \mathrm{Na}^{+}$complexes while a distinct phase separation is observed in the EO-PFPE electrolyte 32 (Figure 3c, Figure S14). It can also be observed that $\mathrm{Na}$ ions primarily locate in the 
1 PEG-rich phase, forming EO-Na ${ }^{+}$complexes, which explains the high dependence of

$2 T_{\mathrm{g}}$ on NaFSI concentrations shown in the DSC results in Figure $1 \mathrm{~b}$.

3 Based on the calculated trajectories, we determined the binding energies between

4 different species in the system was calculated. Figure $3 \mathrm{~d}$ compares the binding energies

5 between NaFSI and different components within the electrolytes (also seen in Figure

6 S15). Compared with EO-CTRL, there is evidence of weakened interactions between

7 EO-PFPE polymer chains and $\mathrm{Na}^{+}$ions $\left(-79.4 \mathrm{kcal} \mathrm{mol}^{-1} v s-98.3 \mathrm{kcal} \mathrm{mol}^{-1}\right)$ with the

8 binding energy between EO-PFPE and FSI $^{-}$doubled. This suggests that the addition of

9 PFPE moieties into a PEG matrix will help 'release' more $\mathrm{Na}^{+}$while restricting the 10 mobility of FSI anions, leading to increased $t_{\mathrm{Na}+}$ (Figure 2e). ${ }^{55}$ Another benefit of using

11 PFPE blocks is the decrease in association energy between $\mathrm{Na}^{+}$and FSI- This could be 12 rationalized by the additional FSI-polymer interactions, which lowers the binding 13 energy between $\mathrm{Na}$ and FSI ions.

(a)
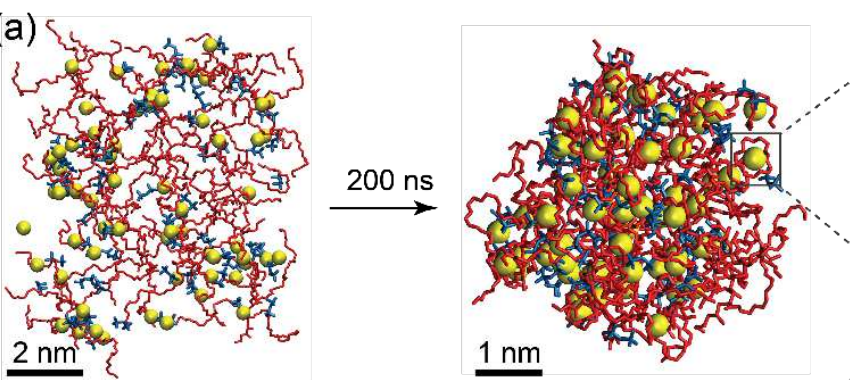

(c)

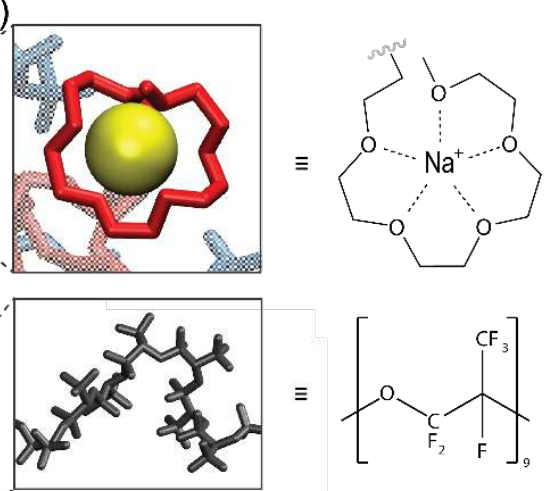

(b)
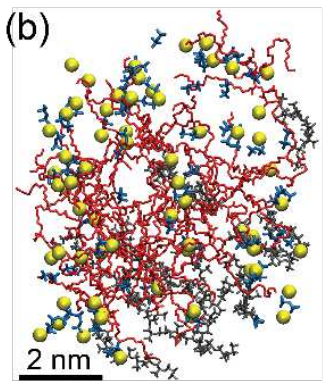

$200 \mathrm{~ns}$

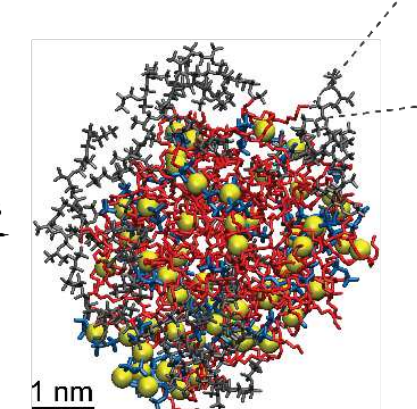

(d)

\begin{tabular}{|c|c|c|}
\cline { 2 - 3 } \multicolumn{1}{c|}{} & EO-PFPE & EO-CTRL \\
\hline $\mathrm{Na}^{+}$to polymer & -79.4 & -98.3 \\
\hline $\mathrm{FSI}^{-}$to polymer & -14.6 & -6.3 \\
\hline $\mathrm{Na}^{+}$to $\mathrm{FSI}^{-}$ & -122.6 & -126.1 \\
\hline
\end{tabular}

Figure 3. MD simulations of (a) EO-CTRL polymer electrolyte and (b) EO-PFPE polymer electrolyte. The EO/Na ${ }^{+}$ratio is equal to $8 / 1 . \mathrm{Na}^{+}=$yellow spheres; $\mathrm{FSI}^{-}=$ blue; EO chains = red; fluorinated fragment of the polymer $=$ grey.

(c) Example of crown ether-like complex between $\mathrm{Na}^{+}$cations and $\mathrm{EO}$ units of the polymer. (d) The calculated binding energies between polymer-polymer, $\mathrm{Na}^{+}$-polymer, $\mathrm{FSI}^{-}$-polymer and $\mathrm{Na}^{+}-\mathrm{FSI}^{-}$for last $1 \mathrm{~ns}$ of $200 \mathrm{~ns}$ simulation, normalized per 1 mole of ion. 
2 The formation of a stable SEI layer between the electrolyte and the Na-metal anode is

3 one of the most effective strategies for improving long-term cycling stability of Na-

4 metal batteries, and to further inhibit short-circuits caused by Na dendrite growth. ${ }^{52}$ To

5 evaluate the electrochemical stability of the EO10-PFPE electrolyte against $\mathrm{Na}$ metal,

6 symmetric $\mathrm{Na} / \mathrm{Na}$ cells were assembled for testing $\mathrm{Na}$ plating/stripping performance,

7 long-term stability and comparison with the EO10-CTRL electrolyte (Figure 4).

8 Impressively, the EO10-PFPE/PVDF composite exhibits extremely stable $\mathrm{Na}$

9 plating/striping behavior at high current density of $0.5 \mathrm{~mA} \mathrm{~cm}{ }^{-2}\left(0.5 \mathrm{mAh} \mathrm{cm}^{-2}\right)$ for 200

10 cycles without significant voltage oscillation (green, Figure $4 \mathrm{~b}$ ). In contrast, the EO10-

11 CTRL electrolyte can only be cycled at a much lower current density of $0.1 \mathrm{~mA} \mathrm{~cm}^{-2}$

$12\left(0.1 \mathrm{mAh} \mathrm{cm}^{-2}\right)$. A severe voltage oscillation is observed, between $50-150 \mathrm{~h}$ in this

13 case, suggesting the formation $\mathrm{Na}$ dendrites and an unstable SEI. ${ }^{56}$ Further increase in

14 the current density to $0.5 \mathrm{~mA} \mathrm{~cm}^{-2}$ leads to an immediately elevated overpotential and

15 a final shorting failure of the symmetric cell in the control electrolyte (blue, Figure 4b). 


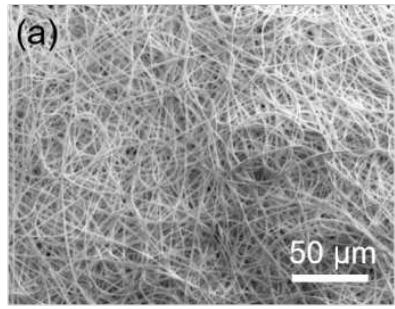

PVDF fibers

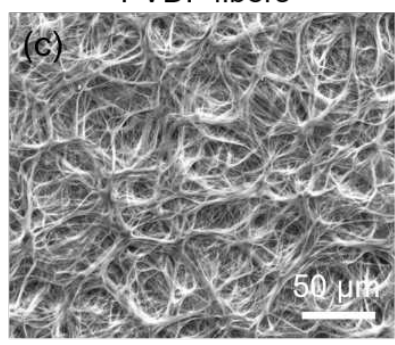

Solupor Seperator

(e)

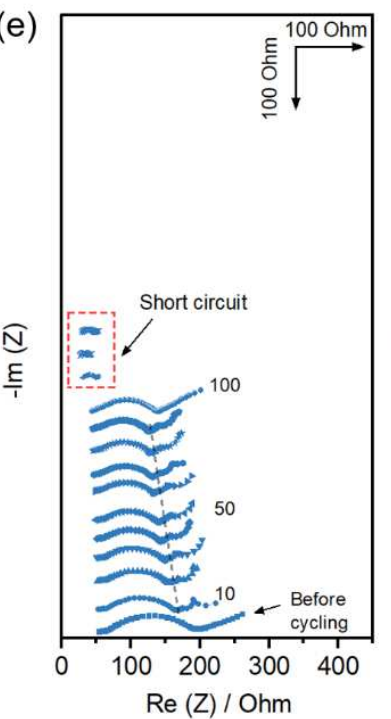

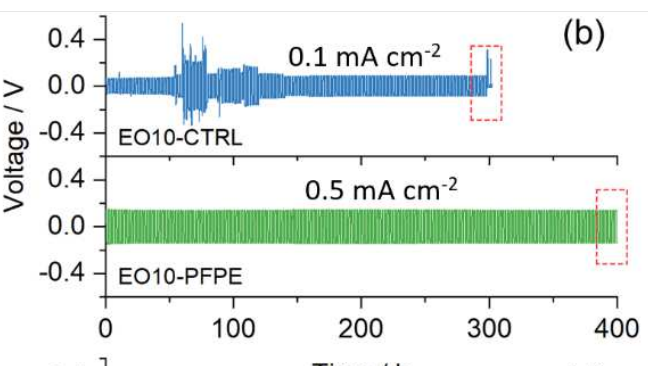
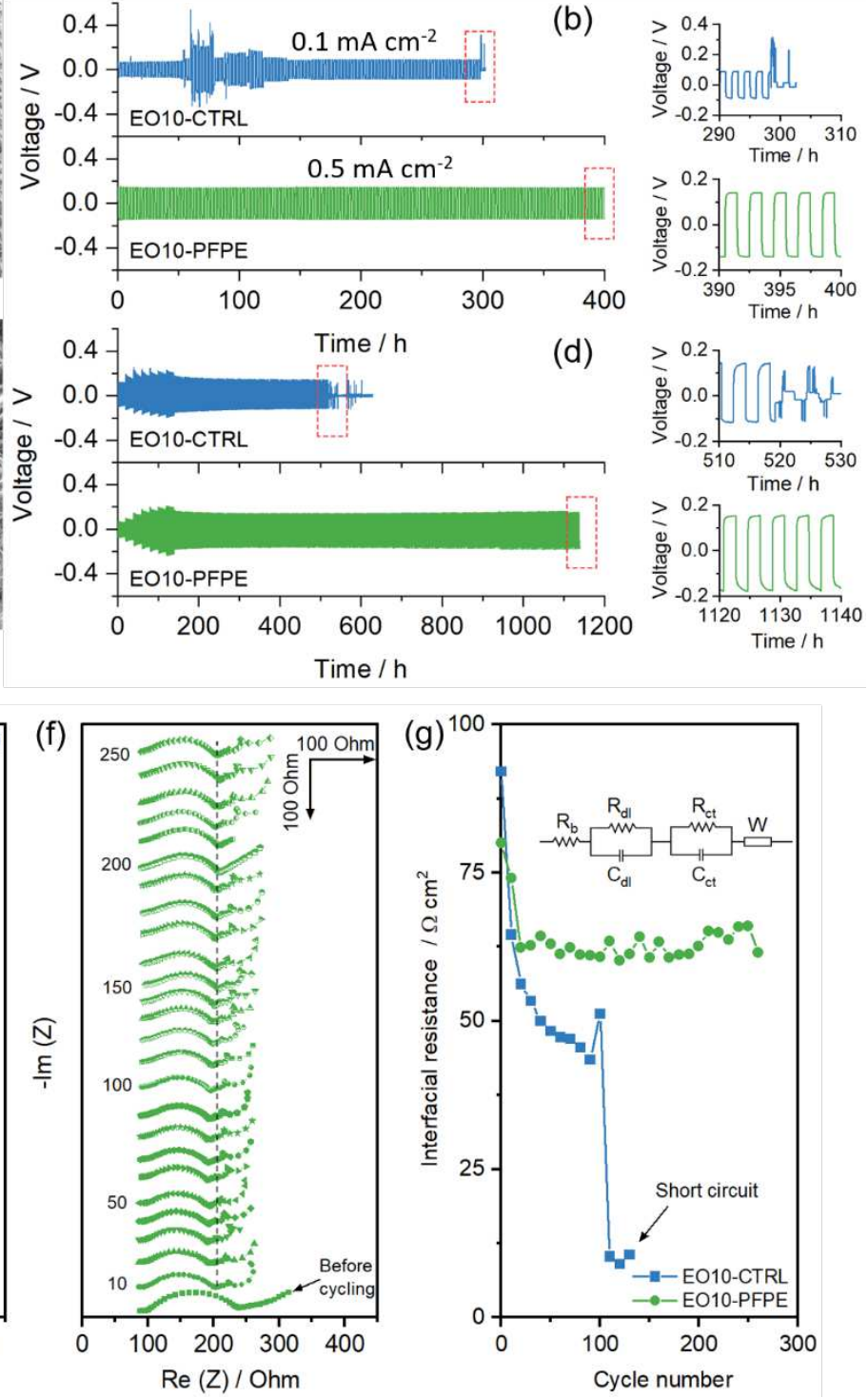

2 Figure 4. (a) SEM image of PVDF electrospun nanofibers and (b) plating/stripping

3 performance of $\mathrm{Na} / \mathrm{Na}$ symmetrical cells using composite electrolytes based on PVDF

4 nanofiber separator. The applied current densities are $0.5 \mathrm{~mA} \mathrm{~cm}{ }^{-2}\left(0.5 \mathrm{mAh} \mathrm{cm}^{-2}\right)$ and

$50.1 \mathrm{~mA}\left(0.1 \mathrm{mAh} \mathrm{cm}^{-2}\right)$ for EO10-PFPE and EO10-CTRL composite electrolytes,

6 respectively. (c) SEM image of the commercial Solupor separator and (d)

7 plating/stripping performance of $\mathrm{Na} / \mathrm{Na}$ symmetrical cells using composite electrolytes

8 based on commercial Solupor separator. During long term cycling tests (after $140 \mathrm{~h}$ ),

9 the applied current density is set at $0.5 \mathrm{~mA} \mathrm{~cm}{ }^{-2}\left(1.0 \mathrm{mAh} \mathrm{cm}^{-2}\right)$. (e) and (f)

10 Electrochemical impedance spectroscopy (EIS) evolution during long-term $\mathrm{Na} / \mathrm{Na}$

11 cycling at $0.5 \mathrm{~mA} \mathrm{~cm}{ }^{-2}\left(1.0 \mathrm{mAh} \mathrm{cm}^{-2}\right)$. The cycling numbers are labeled. $(\mathrm{g})$ The

12 extracted interfacial resistance as function of cycle numbers at $0.5 \mathrm{~mA} \mathrm{~cm}^{-2}(1.0 \mathrm{mAh}$

$13 \mathrm{~cm}^{-2}$ ). The equivalent circuit is shown in the inset. Note: Figure e-g corresponds to the 
1 long-term plating/stripping test at $0.5 \mathrm{~mA} \mathrm{~cm}^{-2}\left(1.0 \mathrm{mAh} \mathrm{cm}^{-2}\right)$ after $140 \mathrm{~h}$ as shown in

2 Figure d. All the cell tests are performed at $80{ }^{\circ} \mathrm{C}$

3 As discussed earlier, the EO10-CTRL electrolyte shows liquid-like behavior and the 4 resultant PVDF composite is a soft and non-free-standing membrane (Figures S7 \& 5 S8), leading to cell failure, even at low current density. To eliminate this mechanical 6 limitation and further confirm the stability of EO10-PFPE, composite electrolytes using a commercial Solupor separator were prepared and used to provide mechanical support. The Solupor separator has a similar porous structure to PVDF (Figure 4c, SEM image). The performance of symmetric cells assembled with Sulopor-based EO10-PFPE and EO10-CTRL electrolytes was tested at $80{ }^{\circ} \mathrm{C}$ and is shown in Figure $4 \mathrm{~d}$. In order to 11 distinguish their different behavior, we designed a new protocol consisting of different current cycling and long-term cycling at high current density. These two symmetric cells both show the capability of cycling at different current density from 0.05 to 0.6 $\mathrm{mA} \mathrm{cm}{ }^{-2}$ (1 h plating/1 h stripping). After $140 \mathrm{~h}$, the cells were cycled at constant current density of $0.5 \mathrm{~mA} \mathrm{~cm}{ }^{-2}$, but with a longer interval of $2 \mathrm{~h}\left(1.0 \mathrm{mAh} \mathrm{cm}^{-2}\right)$. Clearly, the EO10-CTRL/Solupor composite electrolyte exhibits a sudden short-circuit after only 100 cycles while the EO10-PFPE/Solupor composite electrolyte shows extremely stable cycling performance for 400 cycles $(1000 \mathrm{~h})$ under harsh cycling conditions of $1.0 \mathrm{mAh} \mathrm{cm}{ }^{-2}$ per cycle. The superior stability with $\mathrm{Na}$ metal achieved by using the EO10-PFPE electrolyte is further confirmed by the evolution of the impedance spectra. The overall cell resistance (highlighted in dashed lines) of the $\mathrm{Na} / \mathrm{Na}$ symmetric cell with EO10-CTRL/Solupor electrolyte continuously shifts to lower values followed by a dramatic decrease of overall resistance, indicative of cell failure due to short circuits (Figure 4e). In sharp contrast, the symmetric cell assembled with EO10-PFPE/Solupor electrolyte demonstrates ultra-stable cell resistance during long-term cycling for over $1000 \mathrm{~h}$ (Figure 4f). The extracted interfacial resistance summarized in Figure 4g clearly demonstrates that a consistent value is maintained for the composite electrolyte with EO10-PFPE. The ultra-stable performance of the symmetric cells demonstrated by both composite electrolytes, EO10-PFPE/PVDF and

30 EO10-PFPE/Solupor, therefore provides strong evidence of the formation of a stable 31 SEI between the PFPE containing electrolyte and the $\mathrm{Na}$ metal anode. 


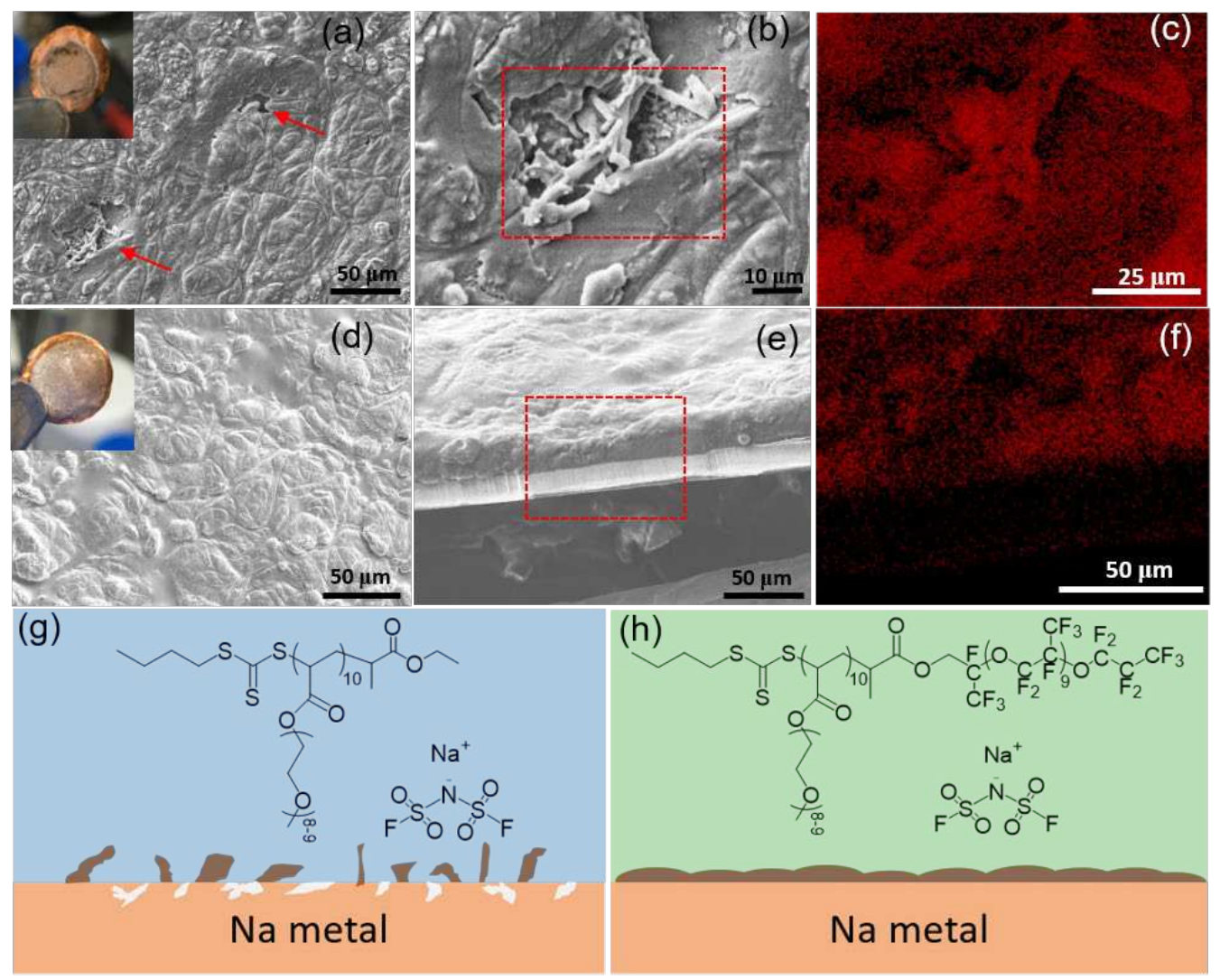

2 Figure 5. Morphologies of deposited Na metal. (a-b) Surface SEM images of deposited

$3 \mathrm{Na}$ in a $\mathrm{Na} / \mathrm{Cu}$ cell with EO10-CTRL electrolyte. (c) The corresponding $\mathrm{Na}$ energy

4 dispersive spectroscopy (EDS) of the highlighted area in (b). (d) Surface SEM and (e)

5 cross-section images of deposited $\mathrm{Na}$ in a $\mathrm{Na} / \mathrm{Cu}$ cell with EO10-PFPE electrolyte. (f)

6 The corresponding Na EDS of highlighted area in (e). (g-h) Schematic illustrations

7 represent the potential SEI formation processes with different electrolytes. The inset in

8 (a) and (d) are the digital photos of deposited $\mathrm{Na}$ on $\mathrm{Cu}$ collectors with EO10-CTRL

9 and EO10-PFPE electrolytes, respectively. The arrows in (a) indicate dendritic 10 deposits.

11 As proposed in previous studies, any morphological changes at the anode surfaces 12 caused by void formation, uneven metal deposition, dendrite growth or SEI formation 13 will affect the overall resistance and final cell performance. ${ }^{52,57,58}$ To further compare 14 the changes in $\mathrm{Na}$ metal morphology during the plating/stripping process, $\mathrm{Na} / \mathrm{Cu}$ cells 15 with different electrolytes were tested. It should be noted that the majority of $\mathrm{Na} / \mathrm{Cu}$ 16 plating/stripping experiments performed previously are based on the use of liquid 17 electrolytes, and the coulombic efficiency (CE) of dry solid electrolytes has been rarely 18 reported. ${ }^{5}$ Nevertheless, the EO10-PFPE composite electrolyte shows promising 
1 stability, up to 400 cycles (average $\mathrm{CE}=89.7 \%$ ) with much lower overpotential, while

2 the EO10-CTRL electrolytes failed after 80 cycles (average $\mathrm{CE}=82.8 \%$, Figure S8a-

3 c). To the best of our knowledge, this is the first plating/stripping demonstration of a

4 solid-state $\mathrm{Na} / \mathrm{Cu}$ cell for such a long time. Also, the lower overpotential convinces the

5 efficient $\mathrm{Na}^{+}$transport of EO10-PFPE as confirmed in Figure 2f. SEM images of the

6 cycled $\mathrm{Na}$ electrode surfaces reveal that uneven $\mathrm{Na}$ deposits were formed on the $\mathrm{Cu}$

7 current collector (indicated by arrows in Figure 5a) when the EO10-CTRL electrolyte

8 was used. The enlarged view shown in Figure 5b and energy dispersive spectroscopy

9 (EDS) $\mathrm{Na}$ mapping in Figure 5c further confirm the formation of dendritic $\mathrm{Na}$,

10 suggesting the failure of the $\mathrm{Na} / \mathrm{Cu}$ cell was due to a short circuit. By contrast, a uniform

11 deposition layer is maintained when EO10-PFPE was used (Figure 5d). Thus, we can

12 conclude that the incorporation of PFPE-moiety into PEG electrolyte greatly inhibits

13 dendrite and void formation, resulting a stable SEI on Na metal surface (Figure 5g-h).

14 It should be also mentioned that the $\mathrm{Na}$ layer was densely deposited on the $\mathrm{Cu}$ current

15 collector (Figures 5e-f). This morphology is beneficial to minimize side reactions and

16 limit SEI growth, which strongly supports the stable plating/stripping performance as

17 demonstrated in $\mathrm{Na} / \mathrm{Na}$ cycling tests in Figure 4f. One may notice that the deposited $\mathrm{Na}$

18 layer in Figure $5 \mathrm{f}$ is surprisingly thick, which likely arises from the accumulation of $\mathrm{Na}$

19 metal during long term cycling and the relatively low CE. 
(a)

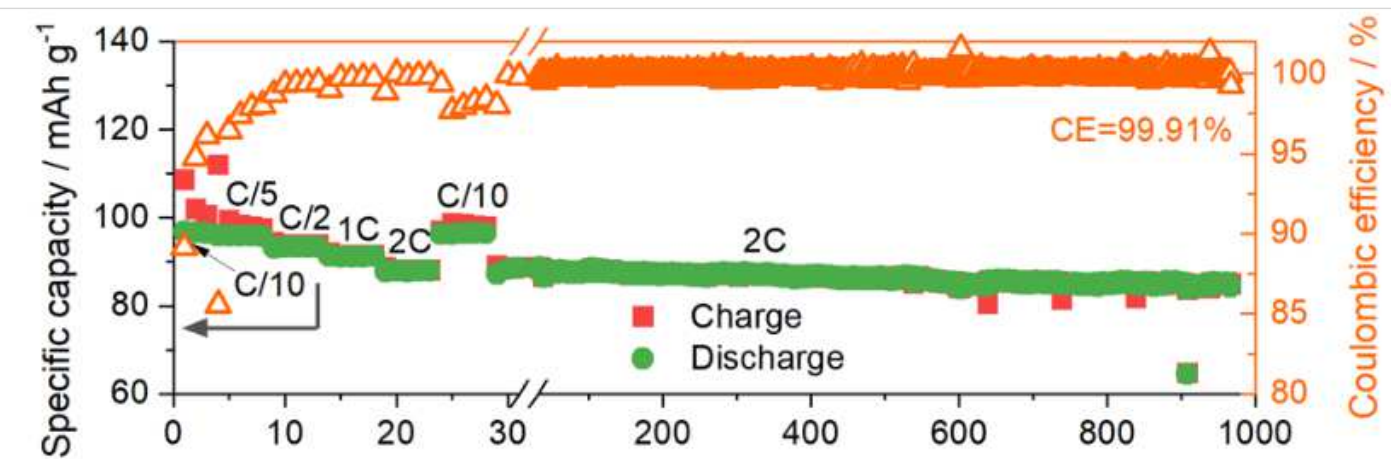

(b)

Cycle number

(c)
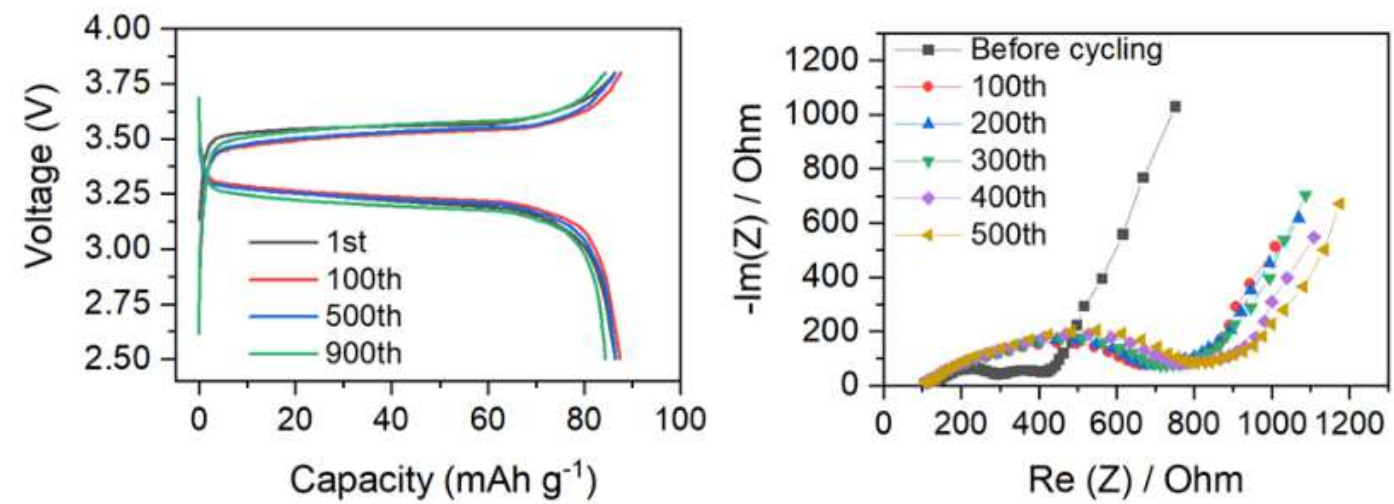

3 Figure 6. Electrochemical performance of Na/NVP full cells assembled with EO10PFPE/PVDF electrolytes. (a) Charge/discharge cycling performance at various $\mathrm{C}$ rates and long-term stability at $\approx 0.2 \mathrm{~mA} \mathrm{~cm}^{-2}(2 \mathrm{C})$. (b) Charge/discharge profiles of different cycles at $\approx 0.2 \mathrm{~mA} \mathrm{~cm}^{-2}(2 \mathrm{C})$. (c) The EIS evolution during long-term cycling at $\approx 0.2$ $\mathrm{mA} \mathrm{cm}{ }^{-2}(2 \mathrm{C})$. The cut-off voltage is $2.5-3.8 \mathrm{~V}$. All tests were performed at $80{ }^{\circ} \mathrm{C}$.

8 The electrochemical performance of the all-solid-state Na/NVP batteries with EO10-

9 PFPE/PVDF composite electrolyte was evaluated and is shown in Figure 6. The $10 \mathrm{Na} / \mathrm{NVP}$ cell was cycled at $\mathrm{C} / 10$ for three cycles, then $\mathrm{C} / 5, \mathrm{C} / 2,1 \mathrm{C}, 2 \mathrm{C}$ and back to

$11 \mathrm{C} / 10$ for five cycles to investigate the capability of the cell at different current densities 12 (Figure 6a). The cell shows an initial discharge capacity of $96.8 \mathrm{mAh} \mathrm{g}^{-1}$, and a 13 relatively low initial $\mathrm{CE}$ of around $90 \%$ at $\mathrm{C} / 10$, which could be related to SEI 14 formation. ${ }^{59}$ When the current density was increased to $\mathrm{C} / 5, \mathrm{C} / 2,1 \mathrm{C}$ and $2 \mathrm{C}$, the 15 discharge capacities were 95.9, 93.1, 91.2 and $87.7 \mathrm{mAh} \mathrm{g}^{-1}$, respectively. The cell 16 promptly recovered to a capacity of $96.3 \mathrm{mAh} \mathrm{g}^{-1}$ when the $\mathrm{C}$ rate was returned to $\mathrm{C} / 10$, 17 which indicates a superior capability of cycling at various $\mathrm{C}$ rates. More impressively, 
1 the all-solid-state Na-metal cell shows extremely long-term stability and high $\mathrm{CE}$ at $2 \mathrm{C}$

$2\left(\approx 0.2 \mathrm{~mA} \mathrm{~cm}^{-2}\right)$. In particular, the discharge capacity only drops from 87.2 to $85.0 \mathrm{mAh}$

$3 \mathrm{~g}^{-1}$ after more than 940 cycles with a capacity retention of $97.5 \%$ (average capacity loss

4 rate of $0.0026 \%$ ) with an average CE higher than $99.9 \%$. The superior cycling stability

5 at high $\mathrm{C}$ rate is also confirmed by the charge/discharge profiles in Figure $6 \mathrm{~b}$ and it is

6 apparent that the charge/discharge curves during the first 500 cycles essentially overlap.

7 In terms of battery resistance, the recorded EIS spectra during 2C cycling

8 measurements are shown in Figure 6c. It is observed that the overall cell resistance

9 increases after 100 cycles, which could result from increased interfacial resistance (e.g.

10 cathode-electrolyte-interphase formation ${ }^{60}$ ) at high current density. Another important

11 observation from Figure $6 \mathrm{c}$ is that the cell resistance only increases from around 700 to

$12790 \mathrm{Ohm}$ during the subsequent cycles, which again highlights the capability of the

13 EO10-PFPE/PVDF electrolyte to sustain high-rate cycling with high stability. Further

14 evidence of long-term stability of the electrolyte is also provided by additional cells

15 cycled at a lower rate of $\mathrm{C} / 2$ shown in Figure S9.

16 The outstanding performance of EO10-PFPE composite electrolyte demonstrated in the

17 study is highlighted by comparison with previous studies based on other polymer or

18 composite electrolytes (Figure 7, Table S3). ${ }^{18,}{ }^{61-72}$ It is clear that the EO10-PFPE

19 composite electrolyte shows the highest capacity retention ( $97.5 \%$ after 940 cycles) and

20 outstanding capacity output in Na-metal full cells and $\mathrm{Na} / \mathrm{Na}$ cells.

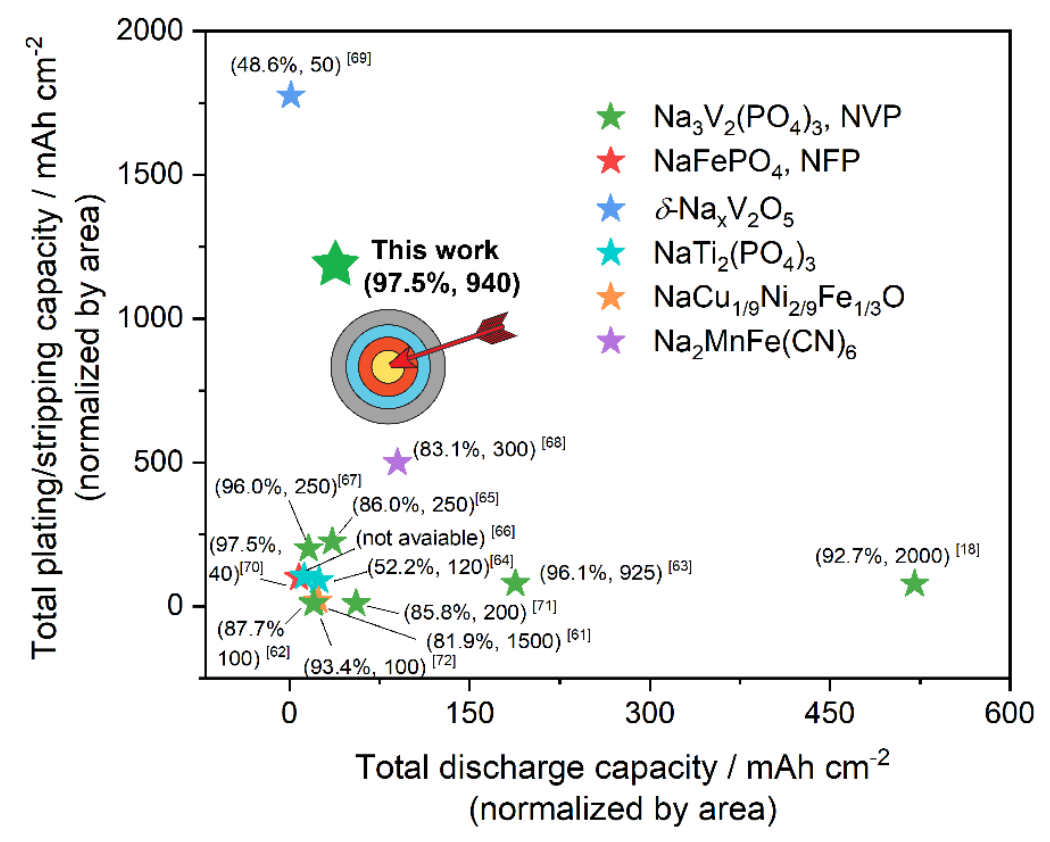


$1 \quad$ Figure 7. The comparison of total plating/stripping capacity (total charge of plated and stripped during whole $\mathrm{Na} / \mathrm{Na}$ tests) and total discharge capacity (discharge capacity $\times$ cycles) based on different electrolytes and cathode materials. The capacities are normalized by area $\left(\mathrm{cm}^{2}\right)$. The numbers in brackets are capacity retention and full cell cycling number, respectively. The arrow signifies the outstanding performance of PFPE-based electrolytes considering plating/stripping and full cell stability against $\mathrm{Na}$ metal.

\section{Conclusions}

9 We have demonstrated an ultra-stable all-solid-state Na-metal battery achieved using a perfluoropolyether (PFPE)-based block copolymer as the solid electrolyte. Our results confirm that the incorporation of PFPE domains segments assist the formation of a selfassembled solid phase, leading to improved mechanical properties with enhanced storage modulus. Additionally, this phase separated microstructure shows synergistic 14 benefits for improving electrolyte performance with molecular dynamics (MD) 15 simulations confirming that the PFPE polymer has weakened interactions with Na ions 16 while enhanced interactions with FSI anions. As a consequence, both the $\mathrm{Na}^{+}$ transference number and $\mathrm{Na}^{+}$conductivity are increased which leads to the composite block copolymer electrolyte showing remarkable long-term cycling stability with a

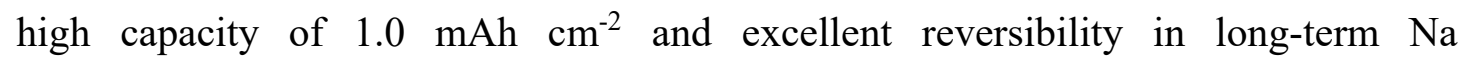
plating/stripping tests. Finally, the assembled solid-state Na-metal batteries (with

$21 \mathrm{Na}_{3} \mathrm{~V}_{2}\left(\mathrm{PO}_{4}\right)_{3}$ cathodes) demonstrate stable rate capability and outstanding 22 charge/discharge reversibility $(\mathrm{CE}=99.91 \%)$ at $\left.2 \mathrm{C}(\approx 0.2 \mathrm{~mA} \mathrm{~cm})^{-2}\right)$ after more than 23900 cycles at elevated temperature of $80^{\circ} \mathrm{C}$.

\section{Experimental}

\section{Materials}

26 The hydroxy-terminated perfluorinated poly(propylene ether) (PFPE-OH, $M \mathrm{w} \sim 1300$ 27 g/mol, CAS Number: 1980064-28-5) was purchased from Apollo Scientific Ltd., UK. 28 Oligo(ethylene glycol) methyl ether acrylate (OEGA, $M \mathrm{w}=480 \mathrm{~g} / \mathrm{mol}$ ) purchased from 29 Sigma Aldrich was passed through basic alumina columns to remove inhibitors before 30 use. The initiator 2,2'-azobis(2-methylpropionitrile) (AIBN) was recrystallized twice 31 from methanol prior to use. The RAFT agent 2-(butylthiocarbonothioylthio)propionic 
1 acid (BTPA) was prepared according to a previously reported procedure. ${ }^{73} \mathrm{~V}_{2} \mathrm{O}_{5}$

2 (99.9\%) and $\mathrm{H}_{2} \mathrm{C}_{2} \mathrm{O}_{4}$ (anhydrous) were and all other chemicals were purchased from

3 Sigma Aldrich and used as received.

4 Synthesis of CTRL- and PFPE-polymers

5 Synthesis of CTRL- and PFPE-polymers was performed according to reported 6 methods. ${ }^{25}$ In a typical experiment for preparing EO10-PFPE, PFPE macro-RAFT 7 agent (187 mg, $0.11 \mathrm{mmol})$, PEGA (770 mg, $1.6 \mathrm{mmol}$ ), and AIBN (3.28 mg, 0.020 $8 \mathrm{mmol})$ were dissolved in trifluorotoluene $(2 \mathrm{~mL})$ and sealed in a $10 \mathrm{~mL}$ flask fitted with

9 a magnetic stirrer bar. The solution was then deoxygenated by purging thoroughly with 10 nitrogen for $15 \mathrm{~min}$, heated to $65^{\circ} \mathrm{C}$ in an oil bath, and allowed to react for $\approx 4 \mathrm{~h}$ with 11 conversion at $\approx 70 \%$. Upon completing the reaction, the solution was precipitated into 12 hexane three times. The precipitate was then dried in a vacuum oven at $60^{\circ} \mathrm{C}$ for $12 \mathrm{~h}$, 13 yielding a yellow viscous solid. Polymers with a range of PFPE compositions were 14 prepared under identical conditions apart from differences in the initial feed amount 15 between PEGA and PFPE macro-RAFT agent. The CTRL sample was prepared with 16 the same procedure in the absence of PFPE macro-RAFT agent. Polymer electrolyte preparation}

The polymer electrolytes were prepared by solvent casting method as described in previous literature. ${ }^{74,75}$ Particularly, PFPE polymer was dried at $50{ }^{\circ} \mathrm{C}$ under vacuum for two days and dissolved in dry acetonitrile together with dry NaFSI salt. The salt concentration was determined by the molar ratio of PEGA groups and NaFSI salt. In this study, high concentration of NaFSI salt was used, and the $\mathrm{EO} / \mathrm{Na}$ ratio was kept as 10/1 and 5/2, corresponding to one and two $\mathrm{Na}^{+}$per PEGA side chain, respectively. For battery tests, composite electrolytes with incorporation of PVDF fibers were used, the composite electrolytes were prepared by casting prepared polymer solution with PVDF matrix $\left(\approx 100 \mu \mathrm{m}\right.$ of thickness) according to our previous work. ${ }^{74}$ The composites with Solupor separators were prepared the same way. The composites were finally dried under vacuum at least for 2 days in order to completely remove solvent and water residuals. 
2 The synthesis of carbon-coated $\mathrm{Na}_{3} \mathrm{~V}_{2}\left(\mathrm{PO}_{4}\right)_{3}$ (NVP) was performed as described

3 elsewhere. ${ }^{76}$ In a typical synthesis, $\mathrm{V}_{2} \mathrm{O}_{5}$ and $\mathrm{H}_{2} \mathrm{C}_{2} \mathrm{O}_{4}$ were dissolved into deionized

4 water and vigorously stirred at $70{ }^{\circ} \mathrm{C}$ for $1 \mathrm{~h}$ in order to obtain a $\mathrm{VOC}_{2} \mathrm{O}_{4}$ solution.

5 Sequentially, $\mathrm{NaH}_{2} \mathrm{PO}_{4}$ and glucose were added to $\mathrm{VOC}_{2} \mathrm{O}_{4}$ solution and the mixture

6 was kept under stirring for additional 10 minutes. Afterwards, N-propanol was further

7 added into $\mathrm{VOC}_{2} \mathrm{O}_{4}$ solution and was left stirring for $30 \mathrm{~min}$. The NVP precursor was

8 obtained by removing the solvent by the aid of a rotary evaporator and the as-obtained

9 solid was further dried under vacuum at $60{ }^{\circ} \mathrm{C}$ for $12 \mathrm{~h}$. Finally, $\mathrm{Na}_{3} \mathrm{~V}_{2}\left(\mathrm{PO}_{4}\right)_{3} / \mathrm{C}$ micro-

10 composites were obtained by pre-treating the precursor at $400{ }^{\circ} \mathrm{C}$ for $4 \mathrm{~h}$ followed by

11 annealing at $750{ }^{\circ} \mathrm{C}$ for $8 \mathrm{~h}$ under inert atmosphere (Ar) at a heating rate of $5{ }^{\circ} \mathrm{C} / \mathrm{min}$.

12 Cathode preparation.

13 Cathode electrodes were prepared by using a slurry composed of $60 \mathrm{wt} \%$ of active 14 material $\left.\mathrm{Na}_{3} \mathrm{~V}_{2}\left(\mathrm{PO}_{4}\right)_{3} / \mathrm{C}\right), 30 \mathrm{wt} \%$ of polymer electrolyte binder and $10 \mathrm{wt} \%$ of 15 conductive carbon (C65, Timcal). The slurry was obtained by initially dissolving the 16 binder in NMP ( $N$-2-methyl-pyrrolidinone) in a small beaker followed by mild stirring 17 for $30 \mathrm{~min}$. In parallel, a pre-weighted amount of NVP cathode material and carbon 18 C65 were ground in an agate mortar for 30 minutes. Afterwards, the ground solid 19 mixture was added to the beaker containing the pre-dissolved binder and a few extra 20 drops of NMP solvent were added to the beaker. In order to obtain a homogeneous 21 slurry, the beaker was left stirring overnight. Subsequently, the viscous slurry was cast 22 onto aluminum foil by using of a doctor blade. The as-obtained film was initially dried 23 at $60^{\circ} \mathrm{C}$ under vacuum for $24 \mathrm{~h}$ and then punched into disks to obtain the electrodes. 24 Before being transferred to the glovebox, the electrodes were further dried in schlenk line for $12 \mathrm{~h}$ at $80{ }^{\circ} \mathrm{C}$ using an air tight vessel. After transferring the vessel to the 26 glovebox (Kiyon, Korea), a set of electrodes (with diameter of $8 \mathrm{~mm}$ ) were weighed and 27 the average active mass loading of the electrodes were around $1.0 \mathrm{mg} \mathrm{cm}^{-2}$.

\section{Characterization}

29 Differential scanning calorimetry (DSC). A Netzsch DSC (214 Polyma) was used to 30 investigate the thermal behaviors of the electrolytes with and without salt. For DSC 31 measurements, an $\mathrm{Al}$ pan was used and 5-10 $\mathrm{mg}$ of material was sealed in an argon 
1 glovebox. Prior to measurements, the DSC instrument was calibrated by using 2 cyclohexane. All samples were cooled to $-120^{\circ} \mathrm{C}$ first and then heated to $180{ }^{\circ} \mathrm{C}$ with 3 a cooling and heating rate of $10{ }^{\circ} \mathrm{C} / \mathrm{min}$. The DSC scans reported in this study were 4 extracted from the second heating scan.

$5 \quad$ NMR spectroscopy. Solution-state ${ }^{1} \mathrm{H}$ and ${ }^{19} \mathrm{~F}$ NMR spectra were recorded on a Bruker 6 Avance $400 \mathrm{MHz}(9.4 \mathrm{~T})$ spectrometer in $\mathrm{CDCl}_{3}$. Chemical shifts $(\delta)$ in ${ }^{1} \mathrm{H} \mathrm{NMR}$ spectra are reported in ppm relative to the residual $\mathrm{CHCl}_{3}(7.26 \mathrm{ppm})$. Solid-state NMR spectra were acquired on a Bruker $300 \mathrm{MHz}$ spectrometer.

Small-angle X-ray scattering (SAXS). SAXS measurements of bulk samples were conducted using a custom-built SAXS diffractometer at the Materials Research 11 Laboratory (MRL) X-ray facility (University of California, Santa Barbara). For these 12 experiments, $1.54 \AA \mathrm{Cu} \mathrm{K \alpha} \mathrm{X}$-rays were generated using a Genix $50 \mathrm{~W}$ X-ray microsource (50 $\mu \mathrm{m}$ micro-focus) equipped with FOX2D collimating multilayer optics 14 (Xenocs, France) and high efficiency scatterless single crystal/metal hybrid slits. 15 Samples were prepared using capillaries for SAXS experiments.

16 Dynamic mechanical thermal analysis (DMTA). Rheological experiments were 17 performed on either TA Instruments ARES dynamic mechanical spectrometer using the $25 \mathrm{~mm}$ parallel plate geometry with a gap of approximately $1 \mathrm{~mm}$ for most experiments.

19 Strain sweep experiments determined the linear viscoelastic region. Isothermal 20 frequency sweeps $(100-0.1 \mathrm{rad} / \mathrm{sec})$ were performed in the linear viscoelastic regime, 21 as confirmed by strain sweep measurements at selected temperatures. Temperature was 22 controlled using the forced convection oven attachment.

23 Electrochemical measurements and full cell tests. Ionic conductivity. The ionic 24 conductivities of PFPE and control electrolytes were measured using electrochemical 25 impedance spectroscopy (EIS) on a Solartron instrument. The frequency range was set 26 from $1 \mathrm{MHz}-0.1 \mathrm{mHZ}$ with an amplitude voltage of $10 \mathrm{mV}$. The samples were sealed 27 in a home-made barrel cell in an Ar-glove box. The temperature was controlled via a 28 Eurotherm 2204 controller, and the temperature range was from 30 to $100{ }^{\circ} \mathrm{C}\left(10{ }^{\circ} \mathrm{C}\right.$ 29 interval). Before each EIS test, the temperature was stabilized for 40 minutes.

30 Coulombic efficiency. The $\mathrm{Na} / \mathrm{Cu}$ cells were assembled in Ar-filled glovebox. The 31 diameters of $\mathrm{Cu}$ and $\mathrm{Na}$ disks are $10 \mathrm{~mm}$ and $8 \mathrm{~mm}$, respectively. For each cycle, the 
1 experiments were done by plating $0.2 \mathrm{mAh} \mathrm{cm}^{-2}$ of $\mathrm{Na}$ on $\mathrm{Cu}$ electrode (1 hour with 2 current density of $0.2 \mathrm{~mA} \mathrm{~cm}-2$ ) then followed by a stripping process at a current 3 density of $0.1 \mathrm{~mA} \mathrm{~cm}^{-2}$ to a cut-off voltage of $1.0 \mathrm{~V}$. All experiments were done at 80 $4{ }^{\circ} \mathrm{C}$.

$5 \mathrm{Na}^{+}$transference number $\left(t_{\mathrm{Na}+}\right)$. The transference number was determined by the 6 method reported previously, and was calculated by the following formula:

$$
t_{N a+}=\frac{R_{c e l l}}{R_{D C}}=\frac{R_{c e l l}}{\frac{V_{D C}}{I_{D C}}}
$$

8 Where the $R_{\text {cell }}$ is the total resistance determined by EIS before DC polarization. The

$9 V_{\mathrm{DC}}$ is the applied polarization voltage of $10 \mathrm{mV}$ and the steady state current $I_{\mathrm{DC}}$ is 10 obtained after 4 hours of stabilization.

11 To determine the $R_{\text {cell, }}$, the following equivalent circuit is used:

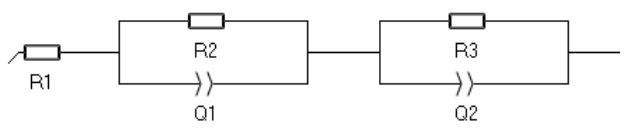

Where $R_{1}$ is the bulk resistance of electrolyte material. $R_{2}$ and $R_{3}$ represent the resistance related with two electrode surfaces.

$\mathrm{Na} / \mathrm{Na}_{3} \mathrm{~V}_{2}\left(\mathrm{PO}_{4}\right)_{3}$ battery tests. All-solid-state sodium-metal batteries comprising the NVP cathode were assembled in CR 2032 coin cells inside the Ar-filled glovebox $\left(\mathrm{O}_{2}\right.$ $<0.1 \mathrm{ppm}, \mathrm{H}_{2} \mathrm{O}<0.1 \mathrm{ppm}$ ). The sodium metal foil (Merck) was rolled and brushed, then cut into anode disks with diameter of $8 \mathrm{~mm}$ (area of $\sim 0.5 \mathrm{~cm}^{2}$ ) as anode. Full cells were cycled in a VMP-3 potentiostat in a potential range of $2.5-3.8 \mathrm{~V}$ at $80{ }^{\circ} \mathrm{C}$.

\section{Theoretical calculations.}

Molecular dynamic (MD) simulations. The molecular structures studied were prepared in GaussView and their atom types and charges were obtained from the CHARMM force field. The CHARMM general force field ${ }^{77,78}$ was implemented for the bond, angle, and dihedral parameters of the ligands and solvent molecules. Non-bonding interactions between these molecules, such as vdW attraction and steric repulsion were described by the Lennard-Jones (LJ) potential, 


$$
U_{L J}(r)=\varepsilon\left[\left(\frac{r_{\min }}{r}\right)^{12}-2\left(\frac{r_{\min }}{r}\right)^{6}\right]
$$

2 where $\varepsilon$ is the minimum (negative) energy of this coupling, and $r$ is a distance where $3 U_{L J}(r)$ has a local minimum, which are provided by the CHARMM force field. Here, 4 the $r^{-12}$ term describes an atomic repulsion, due to overlapping electron orbitals, and 5 the $r^{-6}$ term represents the vdW attractive coupling. The LJ potential implemented in 6 NAMD has a cutoff distance of $1 \mathrm{~nm}$. The electrostatic coupling between ions and partially charged atoms, also contribute to the non-bonding interactions, has the same cutoff distance as the LJ potential, but its long-range part is calculated by the PME method $^{79}$ in the presence of periodic boundary conditions. The molecular dynamic (MD) simulations of the prepared systems were performed with $\mathrm{NAMD}^{80}$ in an NPT

11 ensemble at $\mathrm{T}=298 \mathrm{~K}$ and $\mathrm{P}=1 \mathrm{~atm}$, using the Langevin dynamics with a damping 12 constant of $\gamma_{\text {Lang }}=0.1 \mathrm{ps}^{-1}$ and a time step of $2 \mathrm{fs}$.

13 For MD simulations in the organic solvent droplet, in order to overcome a potentially 14 poor polymer mobility in the simulations, we analyzed the behavior of the same polymer in diethyl ether as a solvent, leading to the well-equilibrated polymer-ion assembly. We run two analogous MD simulations with (i) EO5-PFPE and (ii) EO5CTRL, both in diethyl ether droplets (initially in a form of $7 \times 7 \times 7 \mathrm{~nm}$ cubes, which were placed in $30 \times 30 \times 30 \mathrm{~nm}$ vacuum boxes), composed of:

i) 13 EO5-PFPE molecules, 1987 diethyl ether molecules, $65 \mathrm{Na}+$ cations and the same number of FSI- anions. These numbers yield concentration of the polymer equal to $27.0 \%$ by mass $(63.0 \mathrm{mM})$; EO-to- $\mathrm{Na}^{+}$ratio was equal to $8: 1$.

ii) 13 EO5-CTRL molecules, 1987 diethyl ether molecules, $65 \mathrm{Na}^{+}$cations and the same number of $\mathrm{FSI}^{-}$anions. These numbers yield the same molar concentration of the polymer as in (i), $63.0 \mathrm{mM}$, and $17.8 \%$ by mass; EO-to-Na+ ratio was also equal to $8: 1$.

Binding energy calculations. Based on the obtained trajectories, we calculated the binding energies between the polymer chains, $\mathrm{Na}^{+}$-polymer, FSI-polymer and $\mathrm{Na}^{+}$-FSI pairs using the NAMD Energy toolkit. The calculations were run for the last $1 \mathrm{~ns}$ of the 200 ns simulations. 


\section{Acknowledgements}

The authors acknowledge the support of the Australia-India Strategic Research Fund (AISRF 48515). M. F thanks the Australian Research Council for their Australian Laureate Fellowship program. The research reported here was partially supported by the National Science Foundation (NSF) through the Materials Research Science and Engineering Center at UC Santa Barbara, DMR-1720256 (IRG-2). A.K.W. and C.Z. acknowledge support from the Australian Research Council (CE140100036) and National Health and Medical Research Council for an Early Career Fellowship (APP1157440 to C.Z.). The Australian National Fabrication Facility, Queensland Node, is also acknowledged for access to some items of equipment.

\section{References}

1. Q. Zhao, W. Zhao, C. Zhang, Y. Wu, Q. Yuan, A. K. Whittaker and X. S. Zhao, Energy \& Fuels, 2020, 34, 5099-5105.

2. V. Palomares, P. Serras, I. Villaluenga, K. B. Hueso, J. Carretero-González and T. Rojo, Energy \& Environmental Science, 2012, 5, 5884-5901.

3. X.-B. Cheng, R. Zhang, C.-Z. Zhao and Q. Zhang, Chemical Reviews, 2017, 117, 10403-10473.

4. C. Zhao, Y. Lu, J. Yue, D. Pan, Y. Qi, Y.-S. Hu and L. Chen, Journal of Energy Chemistry, 2018, 27, 1584-1596.

5. Y. Zhao, K. R. Adair and X. Sun, Energy \& Environmental Science, 2018, 11, 2673-2695.

6. Q. Zhao, D. Yang, C. Zhang, X.-H. Liu, X. Fan, A. K. Whittaker and X. S. Zhao, ACS Applied Materials \& Interfaces, 2018, 10, 43730-43739.

7. B. L. Ellis and L. F. Nazar, Current Opinion in Solid State and Materials Science, 2012, 16, 168-177.

8. Y. Lu, L. Li, Q. Zhang, Z. Niu and J. Chen, Joule, 2018, 2, 1747-1770.

9. T. Famprikis, P. Canepa, J. A. Dawson, M. S. Islam and C. Masquelier, Nature Materials, 2019, 18, 1278-1291.

10. L. Porz, T. Swamy, B. W. Sheldon, D. Rettenwander, T. Frömling, H. L. Thaman, S. Berendts, R. Uecker, W. C. Carter and Y.-M. Chiang, Advanced Energy Materials, 2017, 7, 1701003.

11. J. Li, H. Zhu, X. Wang, M. Armand, D. R. MacFarlane and M. Forsyth, Electrochimica Acta, 2015, 175, 232-239.

12. J. Yang, H. Zhang, Q. Zhou, H. Qu, T. Dong, M. Zhang, B. Tang, J. Zhang and G. Cui, ACS Applied Materials \& Interfaces, 2019, 11, 17109-17127.

13. J. Li, H. Zhu, X. Wang, D. R. MacFarlane, M. Armand and M. Forsyth, Journal of Materials Chemistry A, 2015, 3, 19989-19995.

14. I. Aldalur, X. Wang, A. Santiago, N. Goujon, M. Echeverría, M. MartínezIbáñez, M. Piszcz, P. C. Howlett, M. Forsyth, M. Armand and H. Zhang, Journal of Power Sources, 2020, 448, 227424. 
15. M. Forsyth, L. Porcarelli, X. Wang, N. Goujon and D. Mecerreyes, Accounts of Chemical Research, 2019, 52, 686-694.

16. X. Wang, R. Kerr, F. Chen, N. Goujon, J. M. Pringle, D. Mecerreyes, M. Forsyth and P. C. Howlett, Advanced Materials, 2020, 32, 1905219.

17. J. Mindemark, M. J. Lacey, T. Bowden and D. Brandell, Progress in Polymer Science, 2018, 81, 114-143.

18. L. Liu, X. Qi, S. Yin, Q. Zhang, X. Liu, L. Suo, H. Li, L. Chen and Y.-S. Hu, ACS Energy Letters, 2019, 4, 1650-1657.

19. X. Fan, X. Ji, L. Chen, J. Chen, T. Deng, F. Han, J. Yue, N. Piao, R. Wang, X. Zhou, X. Xiao, L. Chen and C. Wang, Nature Energy, 2019, 4, 882-890.

20. Z. Yu, H. Wang, X. Kong, W. Huang, Y. Tsao, D. G. Mackanic, K. Wang, X. Wang, W. Huang, S. Choudhury, Y. Zheng, C. V. Amanchukwu, S. T. Hung, Y. Ma, E. G. Lomeli, J. Qin, Y. Cui and Z. Bao, Nature Energy, 2020, 5, 526533.

21. C. V. Amanchukwu, Z. Yu, X. Kong, J. Qin, Y. Cui and Z. Bao, Journal of the American Chemical Society, 2020, 142, 7393-7403.

22. L. Suo, W. Xue, M. Gobet, S. G. Greenbaum, C. Wang, Y. Chen, W. Yang, Y. Li and J. Li, Proceedings of the National Academy of Sciences, 2018, 115, 1156.

23. D. B. Shah, K. R. Olson, A. Karny, S. J. Mecham, J. M. DeSimone and N. P. Balsara, Journal of The Electrochemical Society, 2017, 164, A3511-A3517.

24. L. Qiao, X. Judez, T. Rojo, M. Armand and H. Zhang, Journal of The Electrochemical Society, 2020, 167, 070534.

25. C. Zhang, S. S. Moonshi, Y. Han, S. Puttick, H. Peng, B. J. A. Magoling, J. C. Reid, S. Bernardi, D. J. Searles, P. Král and A. K. Whittaker, Macromolecules, 2017, 50, 5953-5963.

26. C. Zhang, S. S. Moonshi, W. Wang, H. T. Ta, Y. Han, F. Y. Han, H. Peng, P. Král, B. E. Rolfe, J. J. Gooding, K. Gaus and A. K. Whittaker, ACS Nano, 2018, 12, 9162-9176.

27. S. S. Moonshi, C. Zhang, H. Peng, S. Puttick, S. Rose, N. M. Fisk, K. Bhakoo, B. W. Stringer, G. G. Qiao, P. A. Gurr and A. K. Whittaker, Nanoscale, 2018, 10, 8226-8239.

28. C. Zhang, T. Liu, W. Wang, C. A. Bell, Y. Han, C. Fu, H. Peng, X. Tan, P. Král, K. Gaus, J. J. Gooding and A. K. Whittaker, ACS Nano, 2020, 14, 7425-7434.

29. C. Zhang, L. Li, F. Y. Han, X. Yu, X. Tan, C. Fu, Z. P. Xu and A. K. Whittaker, Small, 2019, 15, 1902309.

30. C. Zhang, R. J. P. Sanchez, C. Fu, R. Clayden-Zabik, H. Peng, K. Kempe and A. K. Whittaker, Biomacromolecules, 2019, 20, 365-374.

31. C. Fu, B. Demir, S. Alcantara, V. Kumar, F. Han, H. G. Kelly, X. Tan, Y. Yu, W. Xu and J. Zhao, Angewandte Chemie, 2020, 132, 4759-4765.

32. C. Fu, Y. Yu, X. Xu, Q. Wang, Y. Chang, C. Zhang, J. Zhao, H. Peng and A. K. Whittaker, Progress in Polymer Science, 2020, 108, 101286.

33. E. Önal, C. Zhang, D. Davarc1, Ü. İşci, G. Pilet, A. K. Whittaker and F. Dumoulin, Tetrahedron Letters, 2018, 59, 521-523.

34. X. Tan, J. Zhong, C. Fu, H. Dang, Y. Han, P. Král, J. Guo, Z. Yuan, H. Peng, C. Zhang and A. K. Whittaker, Macromolecules, 2021, DOI: 10.1021/acs.macromol.1c00096.

35. T. Li, X.-Q. Zhang, P. Shi and Q. Zhang, Joule, 2019, 3, 2647-2661.

36. N. A. Stolwijk, C. Heddier, M. Reschke, M. Wiencierz, J. Bokeloh and G. Wilde, Macromolecules, 2013, 46, 8580-8588.

37. R. He and T. Kyu, Macromolecules, 2016, 49, 5637-5648. 
38. T. Kinsey, K. Glynn, T. Cosby, C. Iacob and J. Sangoro, ACS Applied Materials \& Interfaces, 2020, 12, 44325-44334.

39. W. K. Kipnusu, M. M. Elmahdy, M. Elsayed, R. Krause-Rehberg and F. Kremer, Macromolecules, 2019, 52, 1864-1873.

40. K. Adrjanowicz and M. Paluch, Physical Review Letters, 2019, 122, 176101.

41. S. Napolitano and M. Wübbenhorst, Nature Communications, 2011, 2, 260.

42. T. Zhang, K. I. Winey and R. A. Riggleman, Macromolecules, 2019, 52, 217 226.

43. C. Zhang, M. W. Bates, Z. Geng, A. E. Levi, D. Vigil, S. M. Barbon, T. Loman, K. T. Delaney, G. H. Fredrickson, C. M. Bates, A. K. Whittaker and C. J. Hawker, Journal of the American Chemical Society, 2020, 142, 9843-9849.

44. W. K. Kipnusu, M. Elsayed, W. Kossack, S. Pawlus, K. Adrjanowicz, M. Tress, E. U. Mapesa, R. Krause-Rehberg, K. Kaminski and F. Kremer, The Journal of Physical Chemistry Letters, 2015, 6, 3708-3712.

45. Z. Yu, D. G. Mackanic, W. Michaels, M. Lee, A. Pei, D. Feng, Q. Zhang, Y. Tsao, C. V. Amanchukwu, X. Yan, H. Wang, S. Chen, K. Liu, J. Kang, J. Qin, Y. Cui and Z. Bao, Joule, 2019, 3, 2761-2776.

46. J. Lopez, D. G. Mackanic, Y. Cui and Z. Bao, Nature Reviews Materials, 2019, 4, 312-330.

47. D. H. C. Wong, J. L. Thelen, Y. Fu, D. Devaux, A. A. Pandya, V. S. Battaglia, N. P. Balsara and J. M. DeSimone, Proceedings of the National Academy of Sciences, 2014, 111, 3327.

48. D. H. C. Wong, A. Vitale, D. Devaux, A. Taylor, A. A. Pandya, D. T. Hallinan, J. L. Thelen, S. J. Mecham, S. F. Lux, A. M. Lapides, P. R. Resnick, T. J. Meyer, R. M. Kostecki, N. P. Balsara and J. M. DeSimone, Chemistry of Materials, 2015, 27, 597-603.

49. A. V. Cresce, S. M. Russell, O. Borodin, J. A. Allen, M. A. Schroeder, M. Dai, J. Peng, M. P. Gobet, S. G. Greenbaum, R. E. Rogers and K. Xu, Physical Chemistry Chemical Physics, 2017, 19, 574-586.

50. C. Zhang, D. S. Kim, J. Lawrence, C. J. Hawker and A. K. Whittaker, ACS Macro Letters, 2018, 7, 921-926.

51. C. Zhang, H. Peng and A. K. Whittaker, Journal of Polymer Science Part A: Polymer Chemistry, 2014, 52, 2375-2385.

52. Y. Tian, Y. Sun, D. C. Hannah, Y. Xiao, H. Liu, K. W. Chapman, S.-H. Bo and G. Ceder, Joule, 2019, 3, 1037-1050.

53. Z. Zhang, L. Hu, H. Wu, W. Weng, M. Koh, P. C. Redfern, L. A. Curtiss and K. Amine, Energy \& Environmental Science, 2013, 6, 1806-1810.

54. C. Zhang, S. S. Moonshi, H. Peng, S. Puttick, J. Reid, S. Bernardi, D. J. Searles and A. K. Whittaker, ACS Sensors, 2016, 1, 757-765.

55. L. Cong, J. Liu, M. Armand, A. Mauger, C. M. Julien, H. Xie and L. Sun, Journal of Power Sources, 2018, 380, 115-125.

56. T. Pathirana, R. Kerr, M. Forsyth and P. C. Howlett, Journal of The Electrochemical Society, 2020, 167, 120526.

57. B. Liu, J.-G. Zhang and W. Xu, Joule, 2018, 2, 833-845.

58. Y. Xiang, G. Zheng, Z. Liang, Y. Jin, X. Liu, S. Chen, K. Zhou, J. Zhu, M. Lin, H. He, J. Wan, S. Yu, G. Zhong, R. Fu, Y. Li and Y. Yang, Nature Nanotechnology, 2020, 15, 883-890.

59. Y. Xiao, J.-Y. Hwang, I. Belharouak and Y.-K. Sun, ACS Energy Letters, 2017, 2, 364-372.

60. J.-N. Zhang, Q. Li, Y. Wang, J. Zheng, X. Yu and H. Li, Energy Storage 
Materials, 2018, 14, 1-7.

2 61. Q. Ma, J. Liu, X. Qi, X. Rong, Y. Shao, W. Feng, J. Nie, Y.-S. Hu, H. Li, X. Huang, L. Chen and Z. Zhou, Journal of Materials Chemistry A, 2017, 5, 77387743.

62. C. Ma, K. Dai, H. Hou, X. Ji, L. Chen, D. G. Ivey and W. Wei, Advanced Science, 2018, 5, 1700996.

63. Y. Yao, Z. Wei, H. Wang, H. Huang, Y. Jiang, X. Wu, X. Yao, Z.-S. Wu and Y. Yu, Advanced Energy Materials, 2020, 10, 1903698.

64. W. Zhou, H. Gao and J. B. Goodenough, Advanced Energy Materials, 2016, 6, 1501802.

65. S. Bag, C. Zhou, S. Reid, S. Butler and V. Thangadurai, Journal of Power Sources, 2020, 454, 227954.

66. W. Zhou, Y. Li, S. Xin and J. B. Goodenough, ACS Central Science, 2017, 3, 52-57.

67. Y.-B. Niu, Y.-X. Yin, W.-P. Wang, P.-F. Wang, W. Ling, Y. Xiao and Y.-G. Guo, CCS Chemistry, 2, 589-597.

68. X. Yu, L. Xue, J. B. Goodenough and A. Manthiram, ACS Materials Letters, 2019, 1, 132-138.

69. Y. Zheng, Q. Pan, M. Clites, B. W. Byles, E. Pomerantseva and C. Y. Li, Advanced Energy Materials, 2018, 8, 1801885.

70. S. Malunavar, X. Wang, F. Makhlooghiazad, M. Armand, M. G. Mestres, P. Howlett and M. Forsyth, Journal of Physics: Materials, 2021, submitted.

71. Q. Zhang, Y. Lu, H. Yu, G. Yang, Q. Liu, Z. Wang, L. Chen and Y.-S. Hu, Journal of The Electrochemical Society, 2020, 167, 070523.

72. J.-F. Wu, Z.-Y. Yu, Q. Wang and X. Guo, Energy Storage Materials, 2020, 24, 467-471.

73. C. J. Ferguson, R. J. Hughes, D. Nguyen, B. T. T. Pham, R. G. Gilbert, A. K. Serelis, C. H. Such and B. S. Hawkett, Macromolecules, 2005, 38, 2191-2204.

74. X. Wang, F. Chen, G. M. A. Girard, H. Zhu, D. R. MacFarlane, D. Mecerreyes,

75. X. Wang, G. M. A. Girard, H. Zhu, R. Yunis, D. R. MacFarlane, D. Mecerreyes, A. J. Bhattacharyya, P. C. Howlett and M. Forsyth, ACS Applied Energy Materials, 2019, 2, 6237-6245.

76. Y. Li, Q. An, Y. Cheng, Y. Liang, Y. Ren, C.-J. Sun, H. Dong, Z. Tang, G. Li and Y. Yao, Nano Energy, 2017, 34, 188-194.

77. K. Vanommeslaeghe, E. Hatcher, C. Acharya, S. Kundu, S. Zhong, J. Shim, E. Darian, O. Guvench, P. Lopes, I. Vorobyov and A. D. Mackerell Jr, Journal of Computational Chemistry, 2010, 31, 671-690.

78. W. Yu, X. He, K. Vanommeslaeghe and A. D. MacKerell Jr, Journal of Computational Chemistry, 2012, 33, 2451-2468.

79. P. mesh Ewald, J. Chem. Phys, 1993, 98, 10089-10092.

80. J. C. Phillips, R. Braun, W. Wang, J. Gumbart, E. Tajkhorshid, E. Villa, C. Chipot, R. D. Skeel, L. Kalé and K. Schulten, Journal of Computational Chemistry, 2005, 26, 1781-1802. 


\section{Figures}

(a)

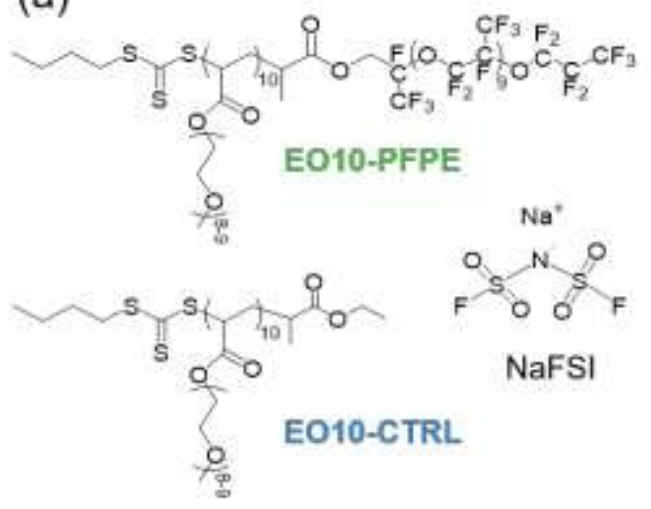

(c)

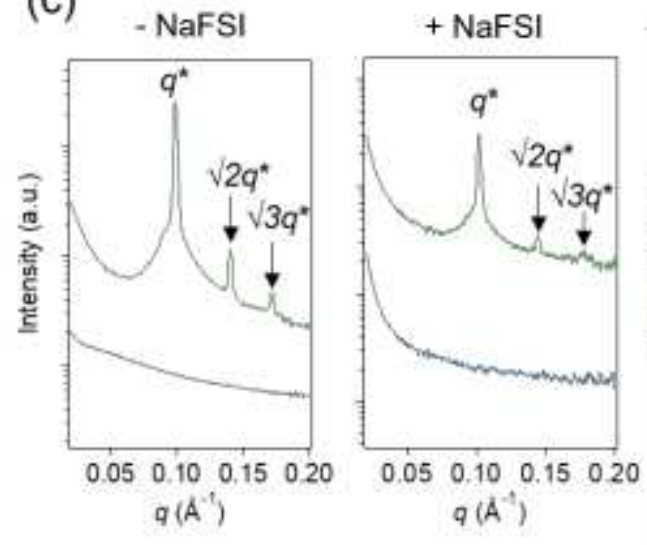

(b)

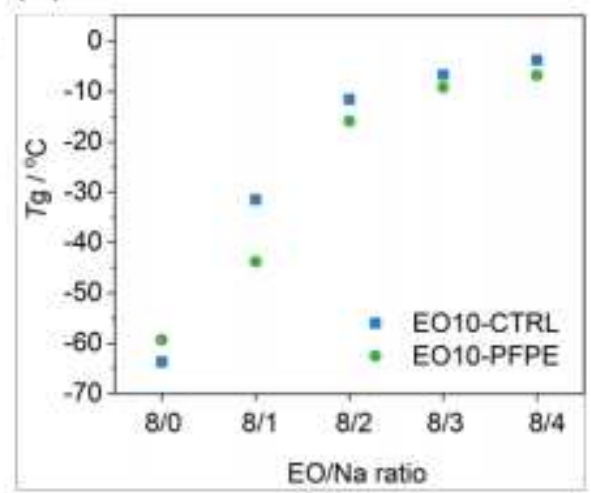

(d)

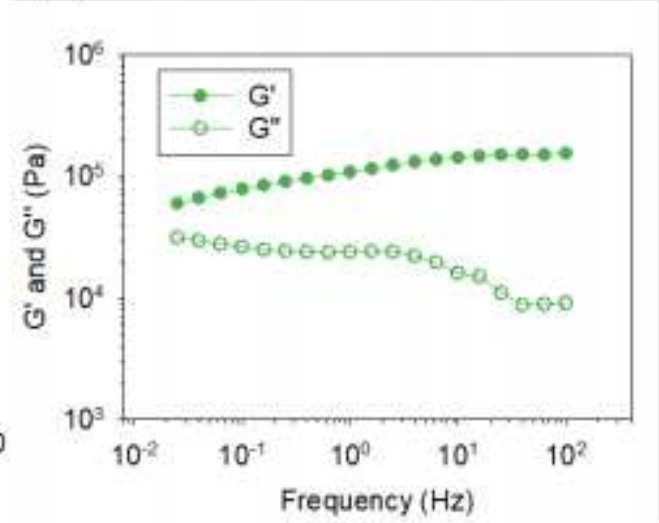

Figure 1

Chemical structures as well as physical and self-assembly properties of PFPE-based polymer electrolytes. 

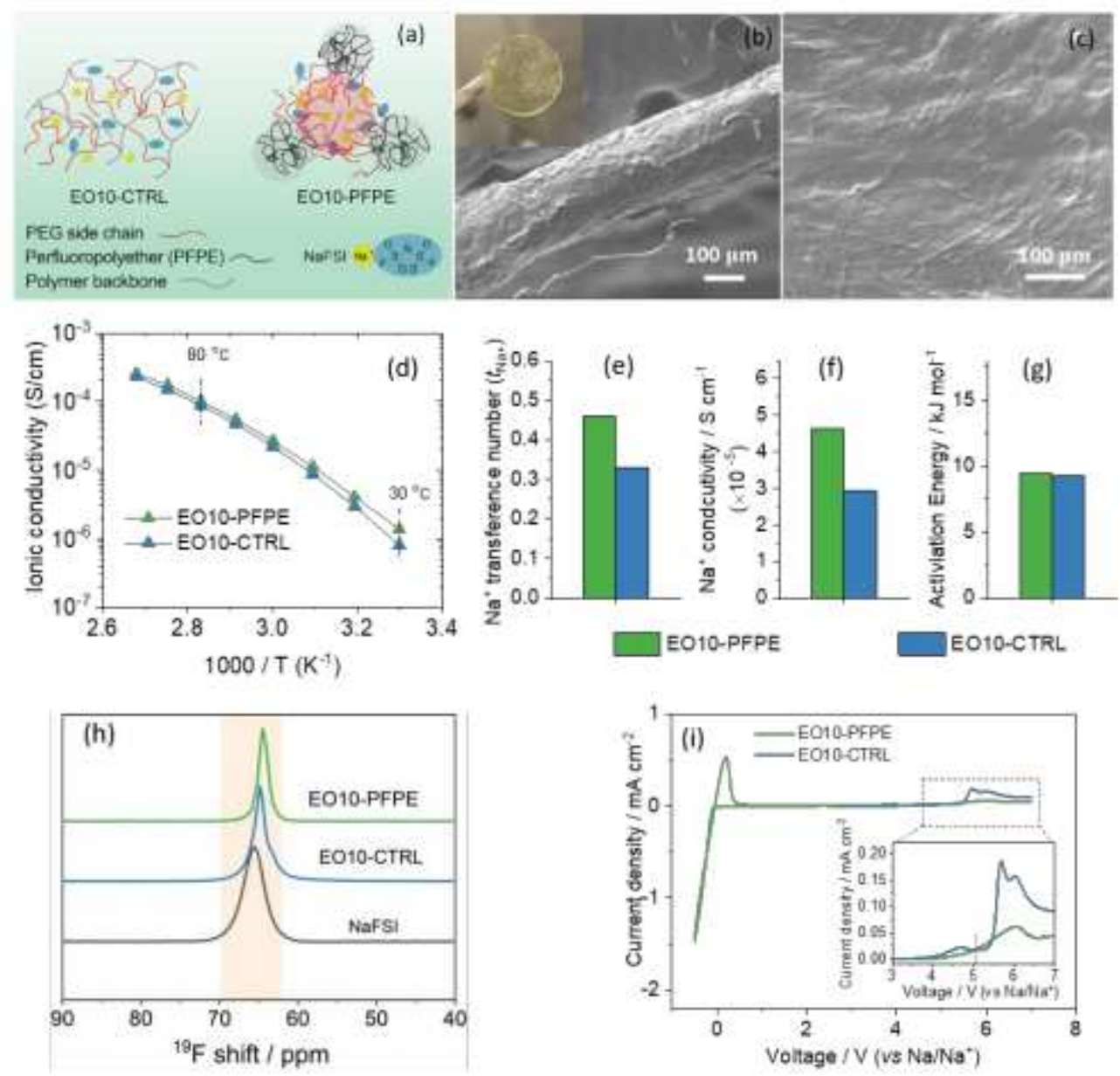

Figure 2

Please see the manuscript file to view the figure caption.

(a)

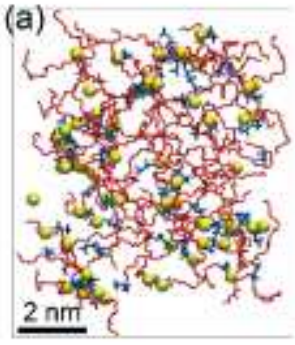

(b)

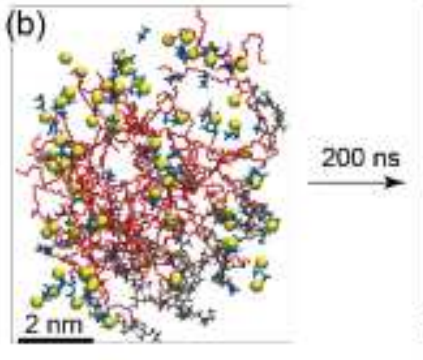

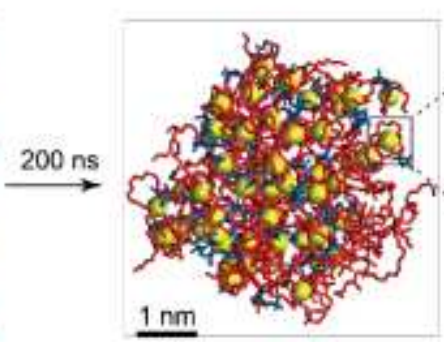

(c)

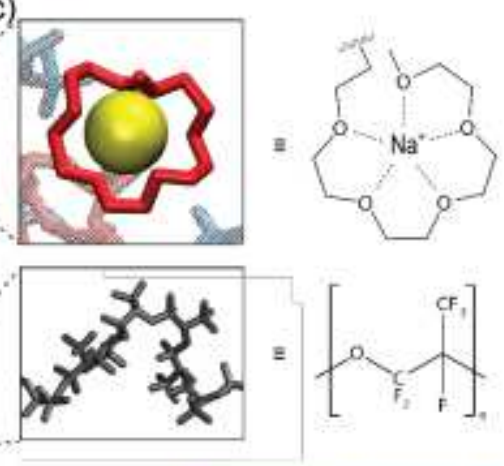

(d)

\begin{tabular}{|c|c|c|}
\hline Na' to polymer & -79.4 & -98.3 \\
\hline FSt to polymer & -14.6 & -6.3 \\
\hline $\mathrm{Na}$ ' to FSt & -122.6 & -126.1 \\
\hline
\end{tabular}

Figure 3 
MD simulations
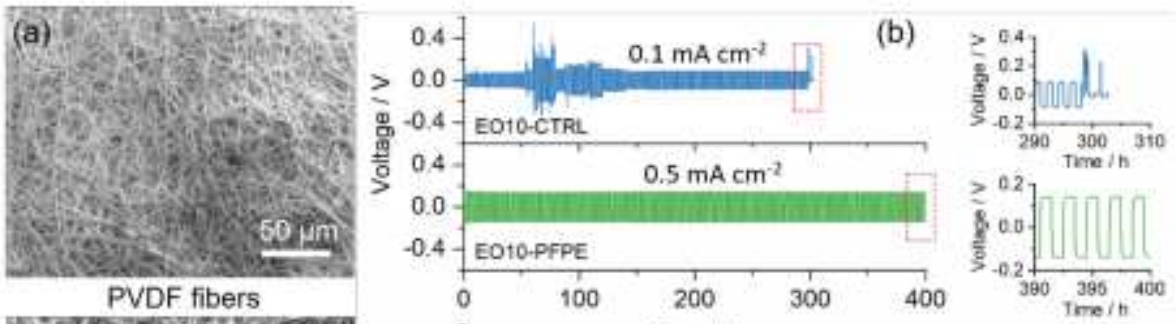

PVDF fibers

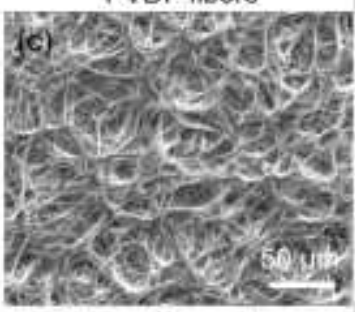

Solupor Seperator
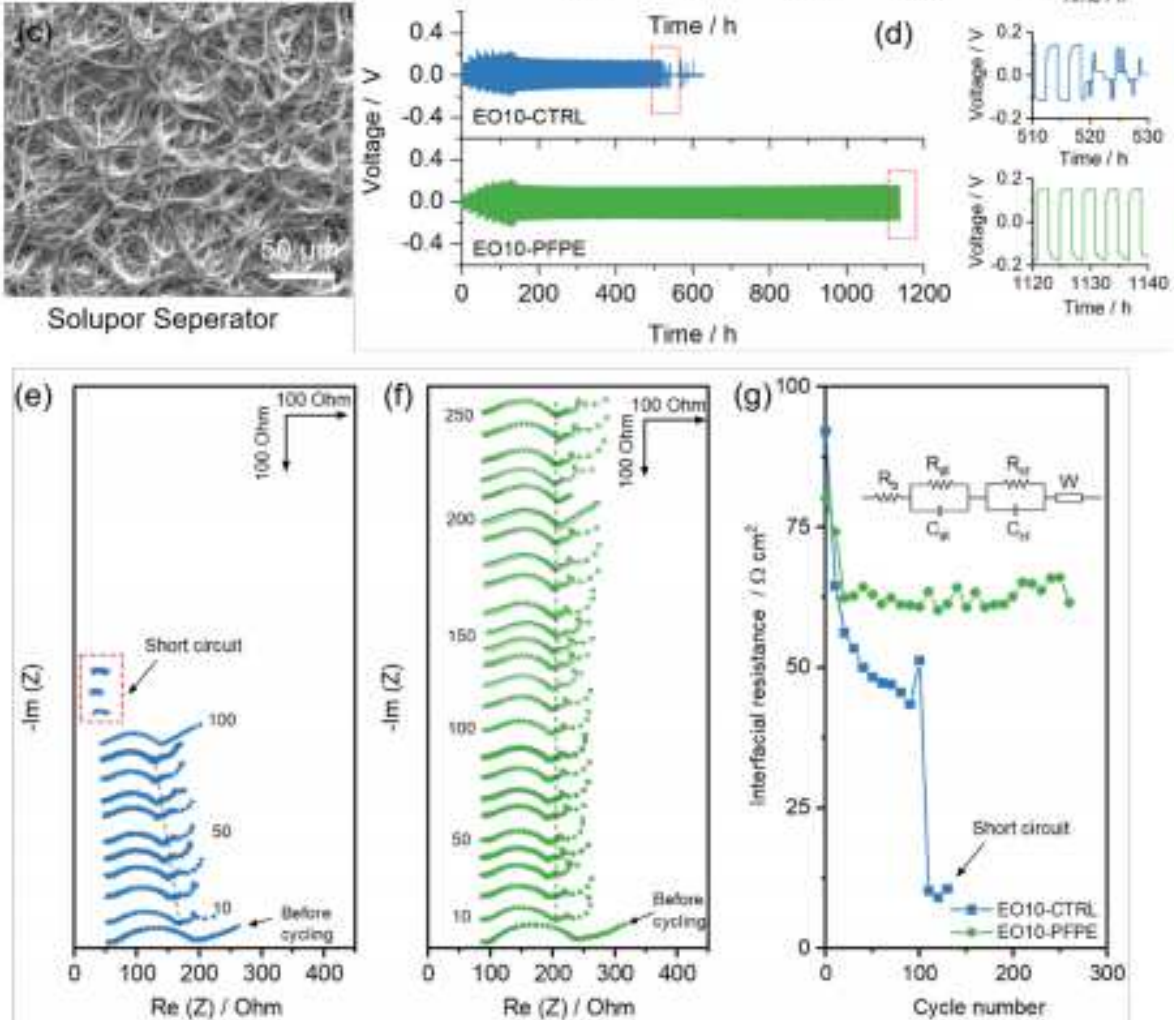

Figure 4

Please see the manuscript file to view the figure caption. 


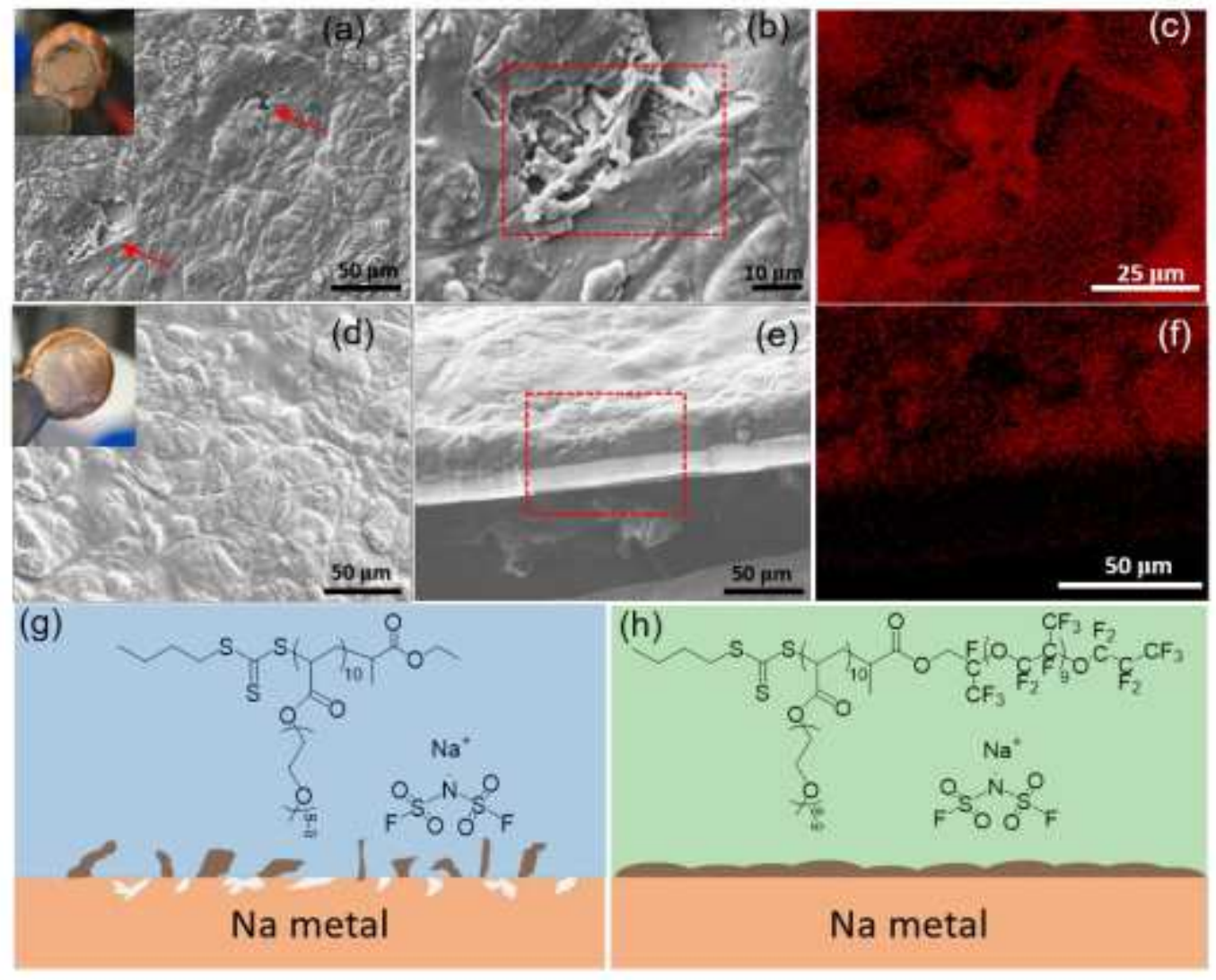

Figure 5

Morphologies of deposited Na metal. 
(a)

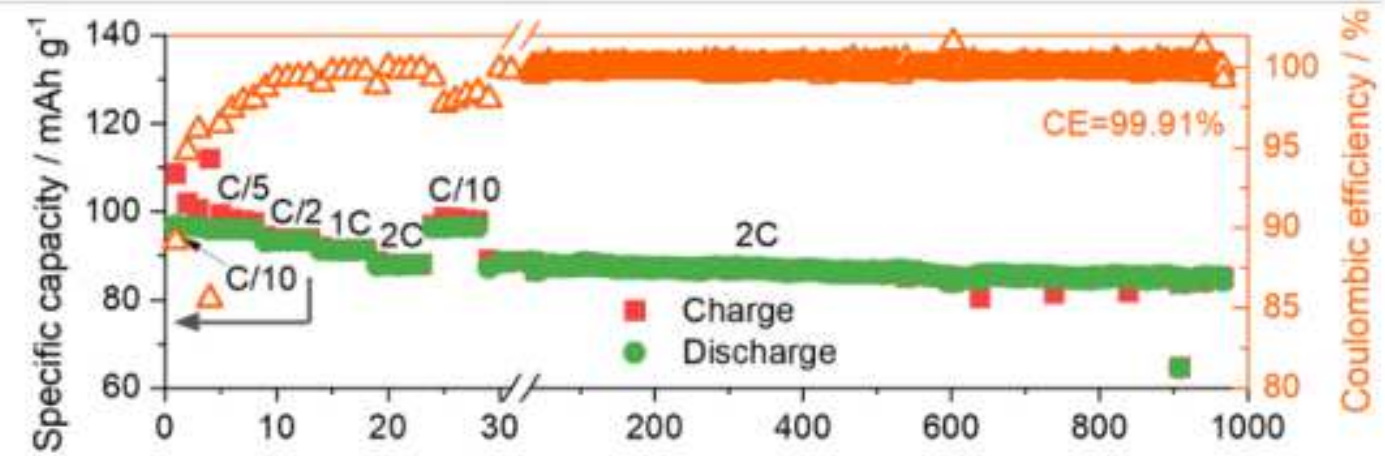

(b)

Cycle number

(c)
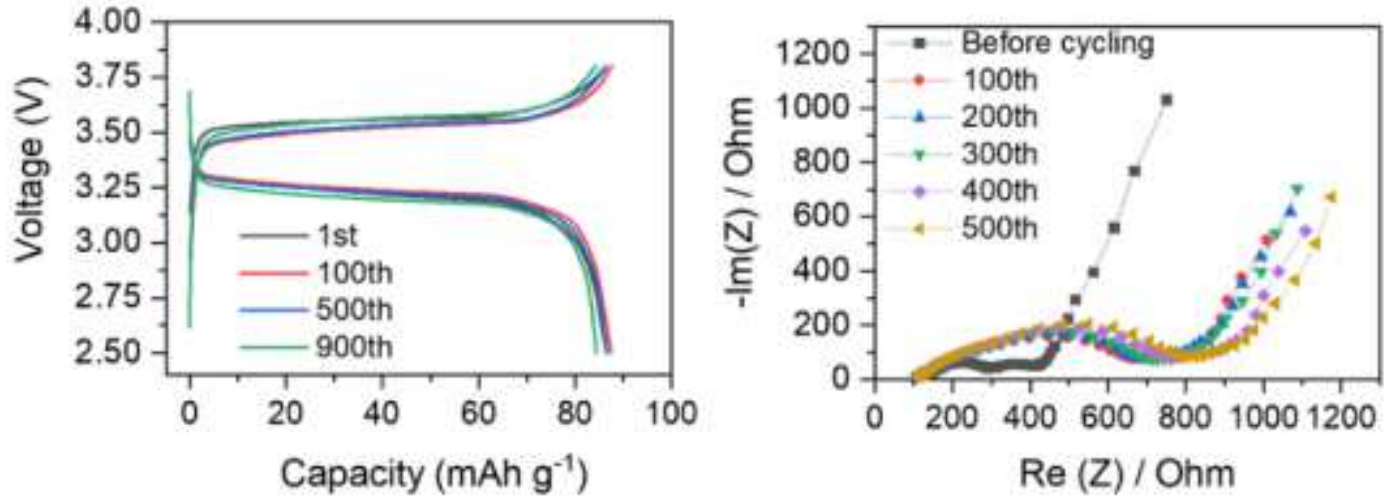

Figure 6

Electrochemical performance of Na/NVP full cells assembled with E010-PFPE/PVDF electrolytes.

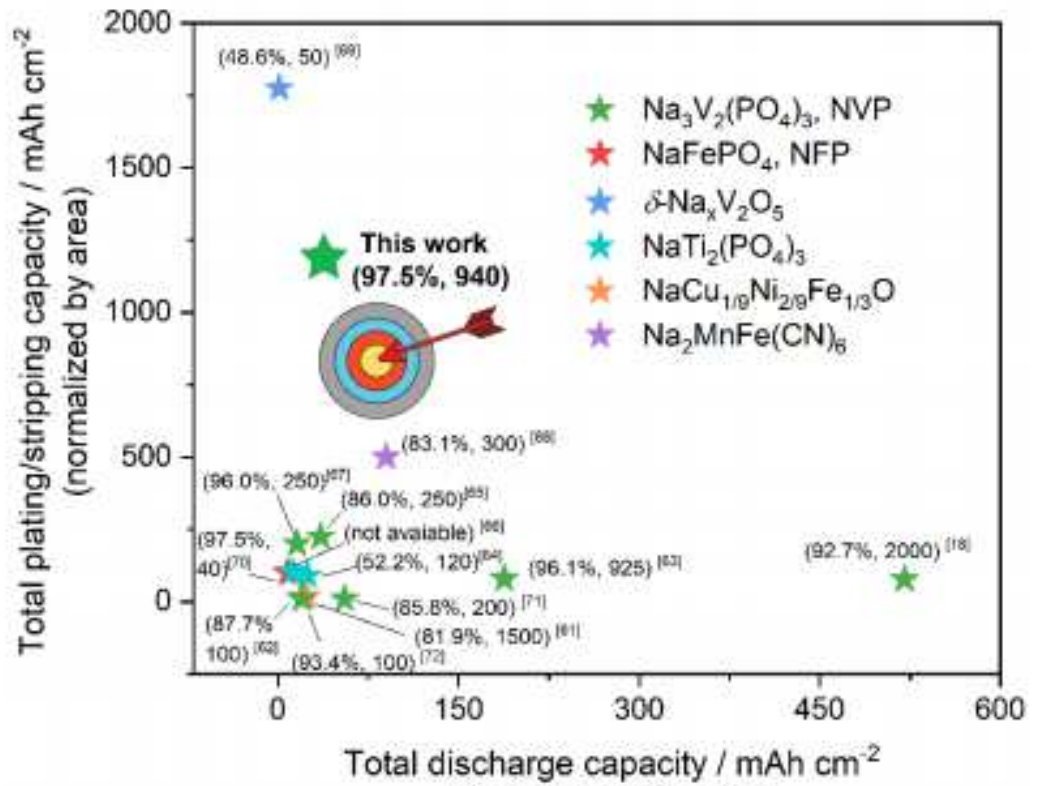

(normalized by area)

Figure 7 
The comparison of total plating/stripping capacity (total charge of plated and stripped during whole $\mathrm{Na} / \mathrm{Na}$ tests) and total discharge capacity (discharge capacity $\times$ cycles) based on different electrolytes and cathode materials.

\section{Supplementary Files}

This is a list of supplementary files associated with this preprint. Click to download.

- SIfinal23032021.pdf 